\title{
Redox Isomeric Ferrocenyl Styrylruthenium Radical Cations with Diphenyl-Substituted $\beta$-Ketoenolato Ligands
}

Christopher Hassenrück, ${ }^{[a]}$ Mykhailo Azarkh, ${ }^{[a]}$ Malte Drescher ${ }^{[a]}$, Michael Linseis, ${ }^{\left[{ }^{[a]}\right.}$ Serhiy Demeshko, ${ }^{[b]}$ Franc Meyer, ${ }^{[b]}$ and Rainer F. Winter ${ }^{*}[a]$

[a] University of Konstanz, Department of Chemistry, Universitätsstraße 10, 78457 Konstanz, Germany

[b] Georg-August-Universität Göttingen, Institut für Anorganische Chemie, Tammannstraße 4, 37077 Göttingen, Germany

Supporting Information

NMR spectra

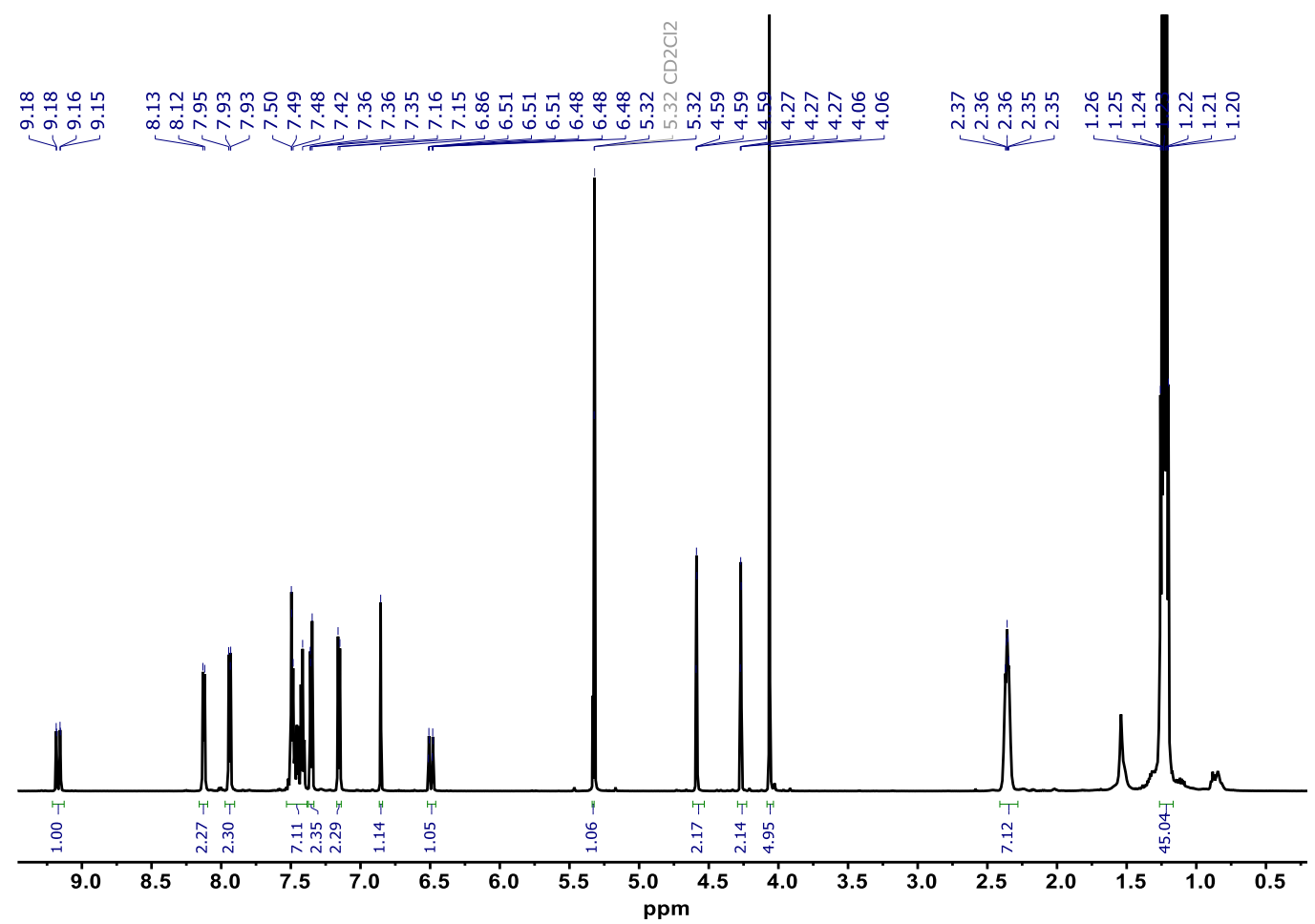

Figure $\mathrm{S} 1 .{ }^{1} \mathrm{H}$ NMR spectrum of $\mathbf{2}-\mathrm{H}$ in $\mathrm{CD}_{2} \mathrm{Cl}_{2}$ at room temperature. 


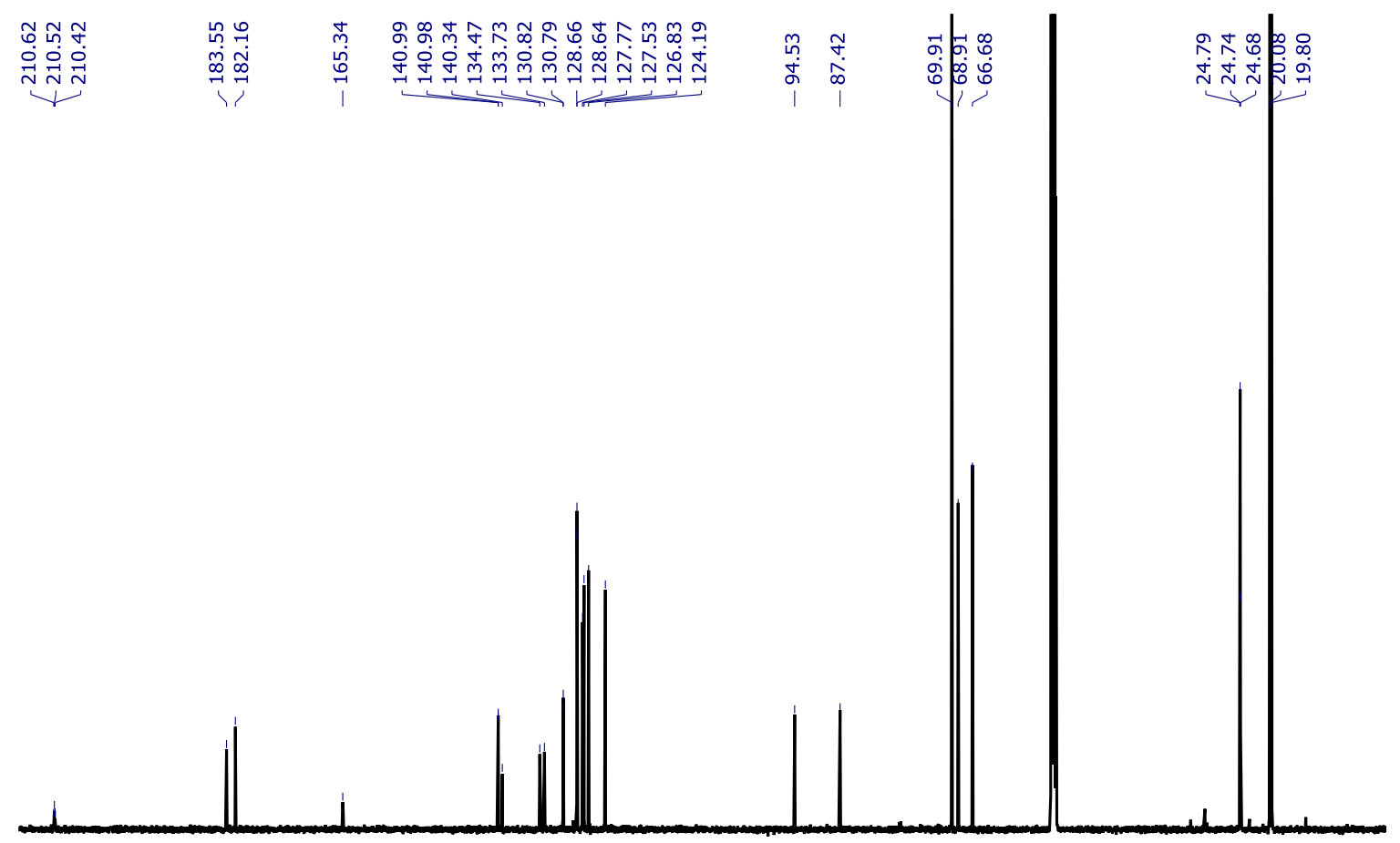

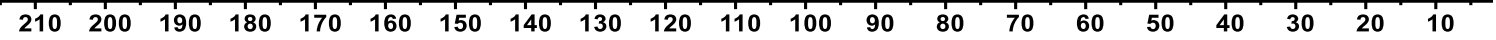
ppm

Figure S2. ${ }^{13} \mathrm{C}$ NMR spectrum of $2-\mathrm{H}$ in $\mathrm{CD}_{2} \mathrm{Cl}_{2}$ at room temperature.

$\underset{\substack{m \\ m}}{\stackrel{m}{i}}$

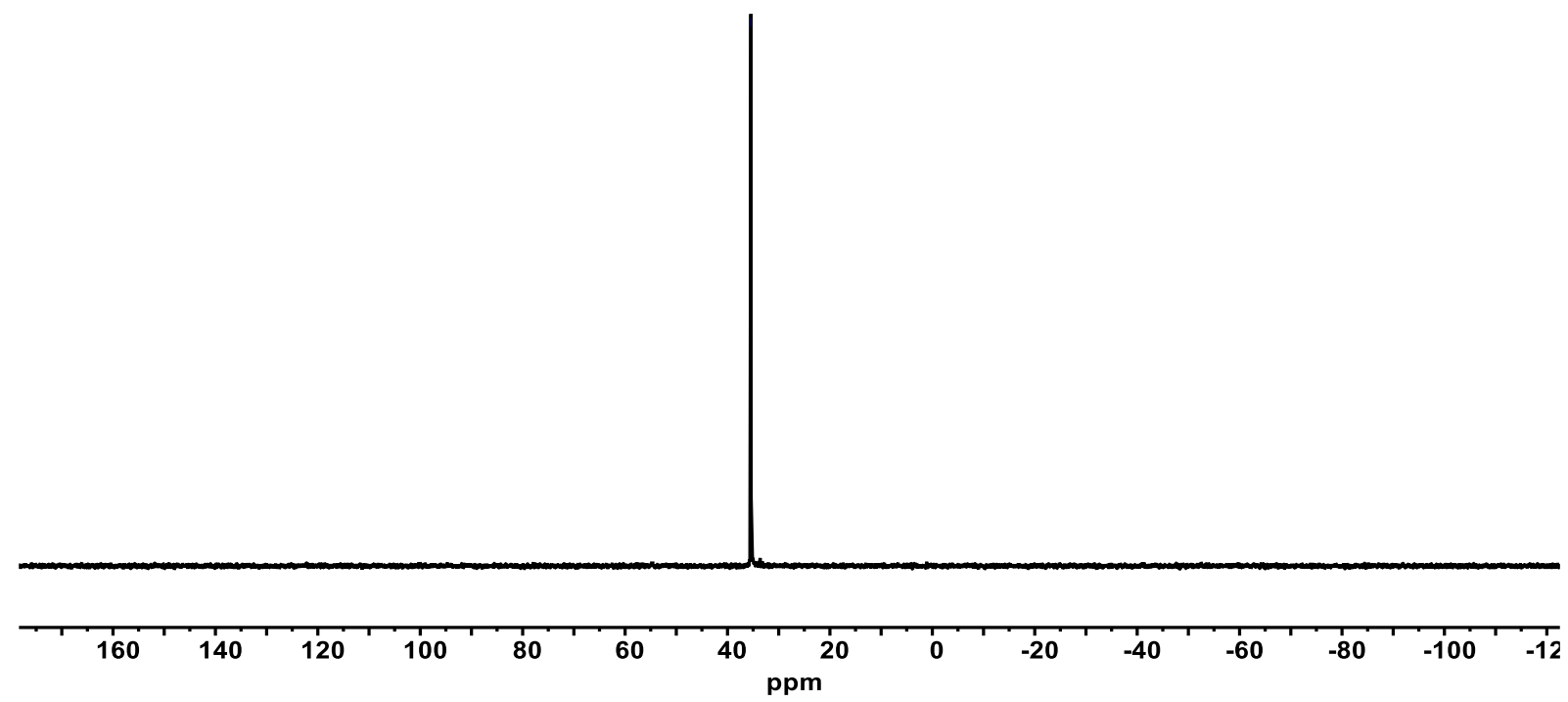

Figure S3. ${ }^{31} \mathrm{P}$ NMR spectrum of $2-\mathrm{H}$ in $\mathrm{CD}_{2} \mathrm{Cl}_{2}$ at room temperature. 


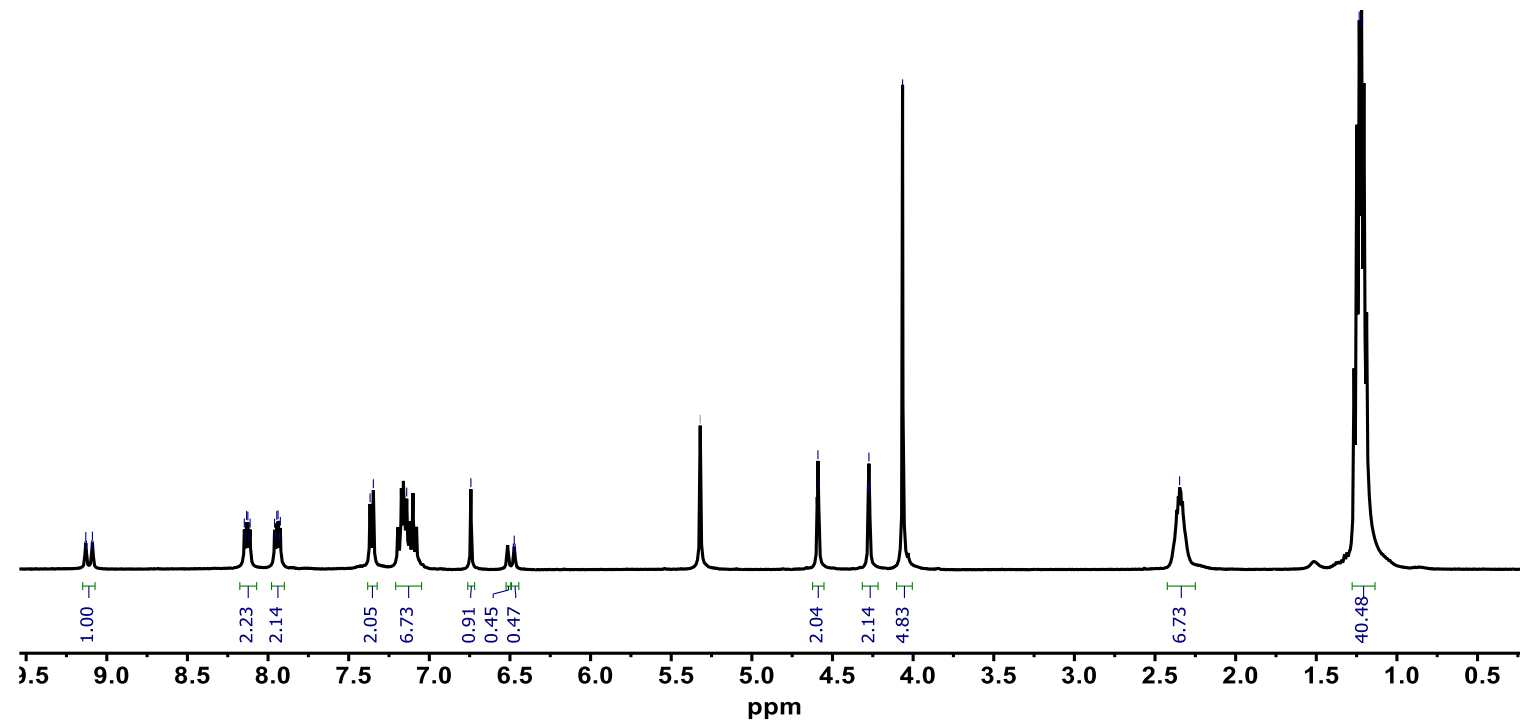

Figure S4. ${ }^{1} \mathrm{H}$ NMR spectrum of $2-\mathbf{F}$ in $\mathrm{CD}_{2} \mathrm{Cl}_{2}$ at room temperature.

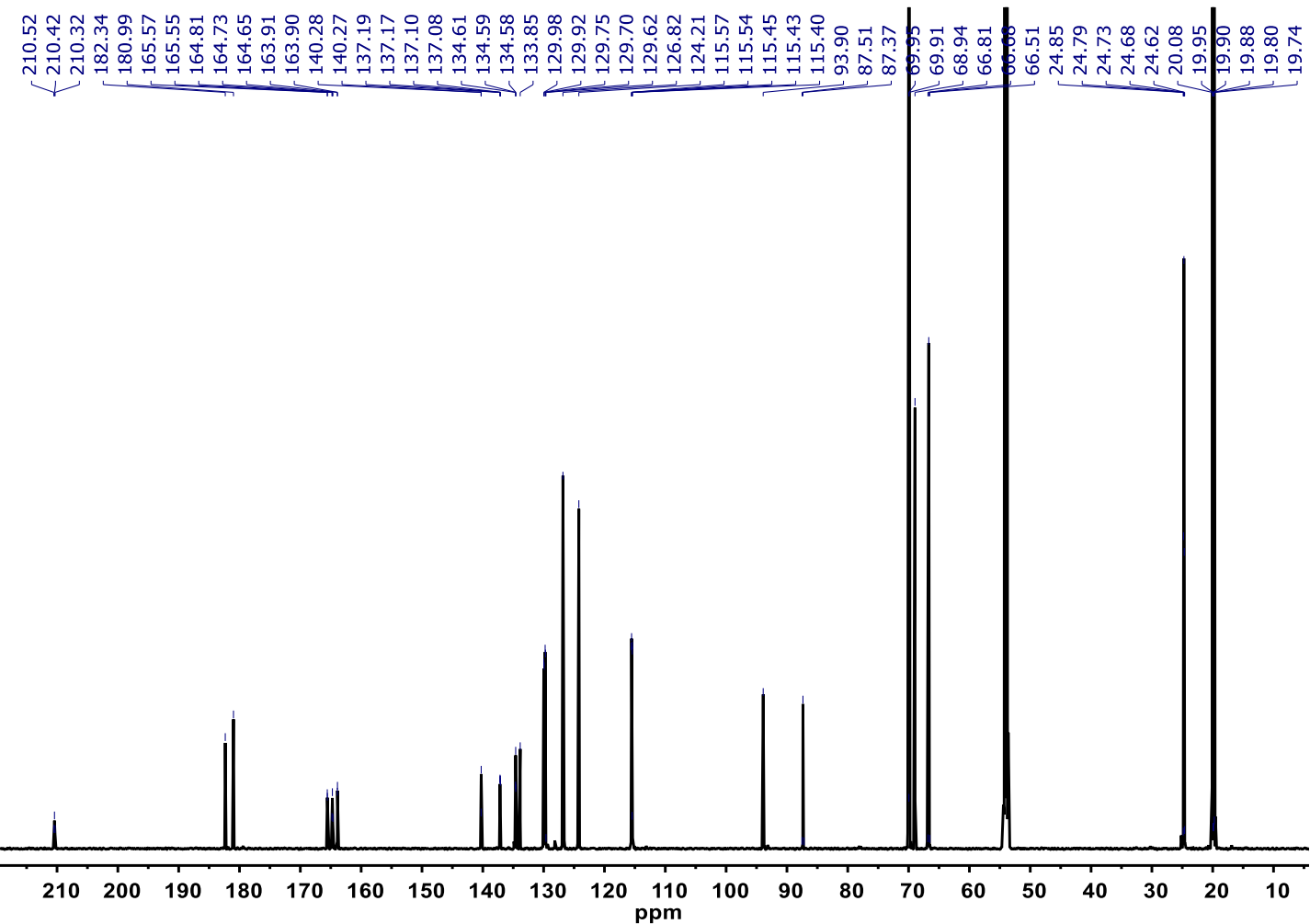

Figure S5. ${ }^{13} \mathrm{C}$ NMR spectrum of 2-F in $\mathrm{CD}_{2} \mathrm{Cl}_{2}$ at room temperature. 


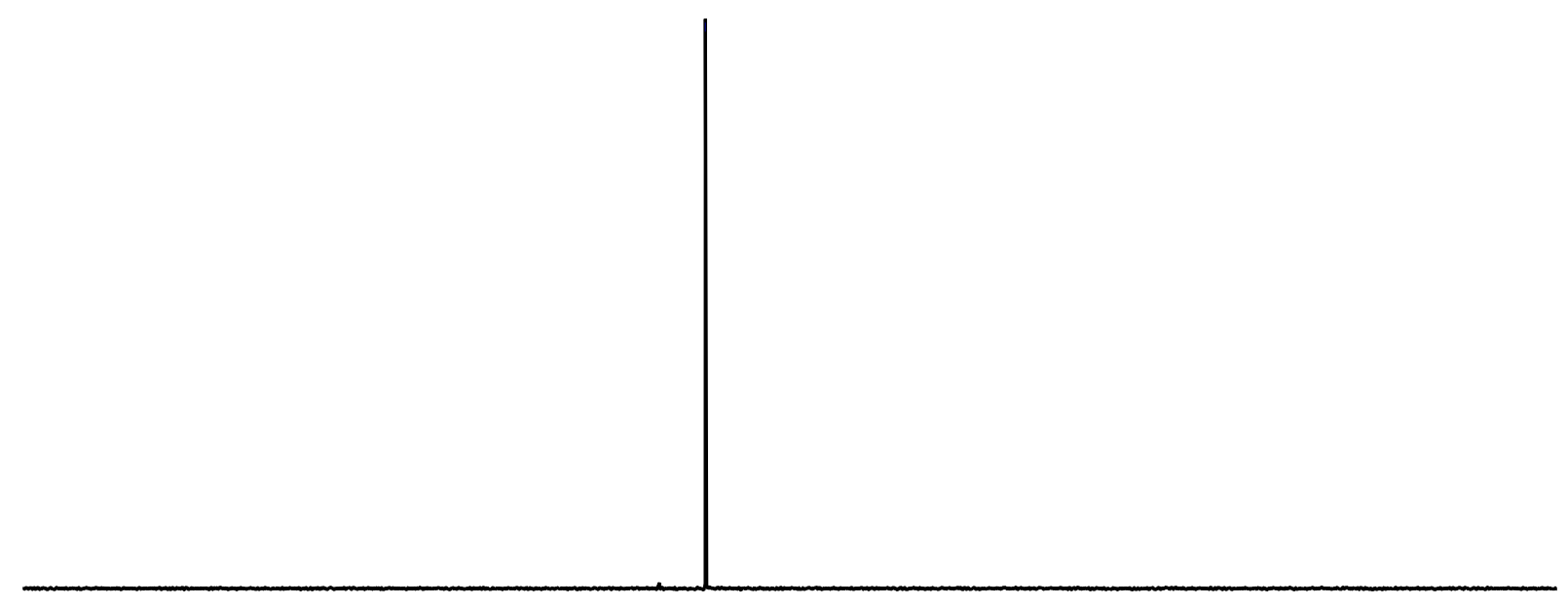

\begin{tabular}{|c|c|c|c|c|c|c|c|c|c|c|c|c|c|c|c|}
\hline 20 & 280 & 240 & 200 & 160 & 120 & 80 & 40 & 0 & -40 & -80 & -120 & -160 & -200 & -240 & -280 \\
\hline
\end{tabular}

Figure S6. ${ }^{31} \mathrm{P}$ NMR spectrum of 2-F in $\mathrm{CD}_{2} \mathrm{Cl}_{2}$ at room temperature.

공

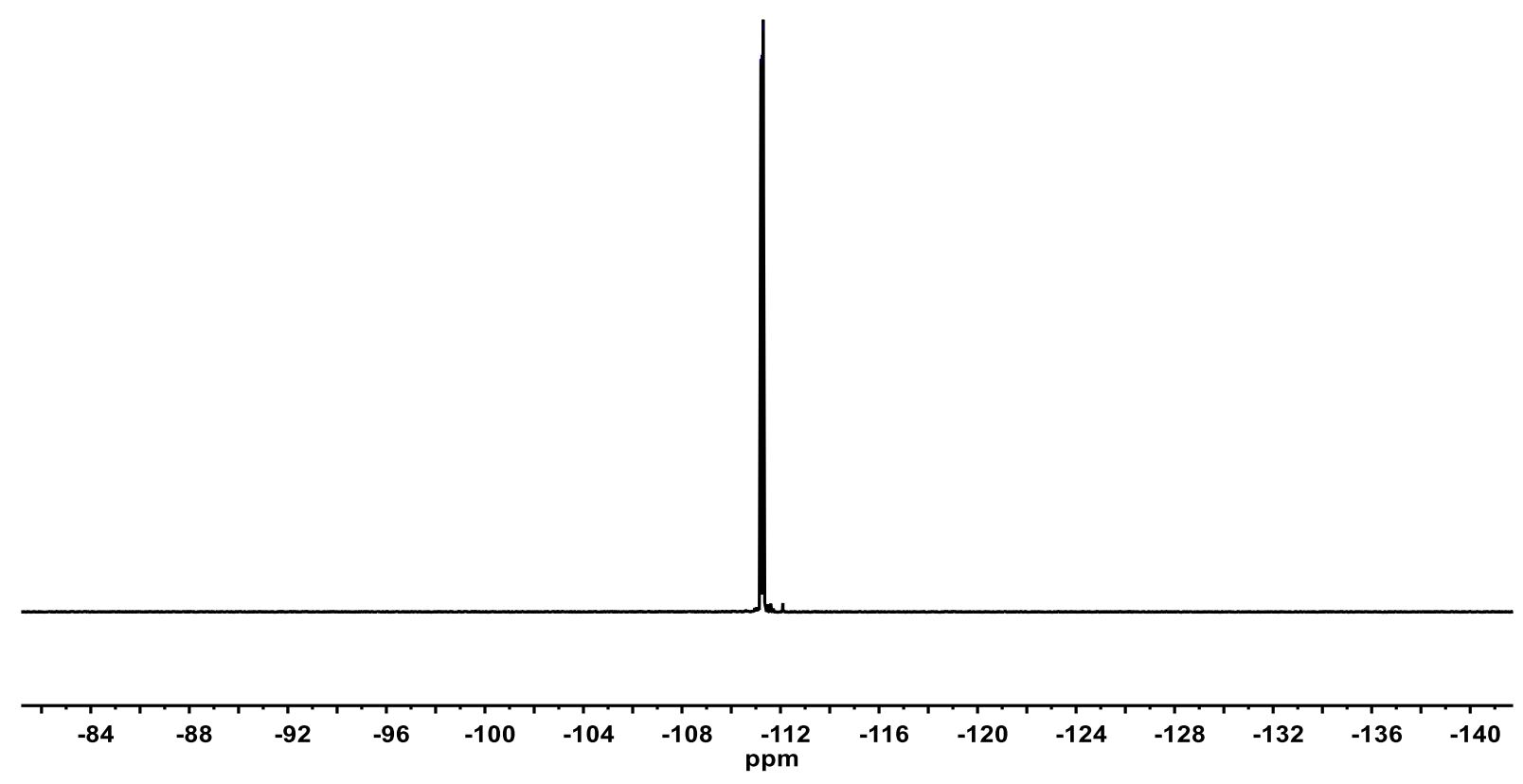

Figure S7. ${ }^{19} \mathrm{~F}$ NMR spectrum of 2-F in $\mathrm{CD}_{2} \mathrm{Cl}_{2}$ at room temperature. 


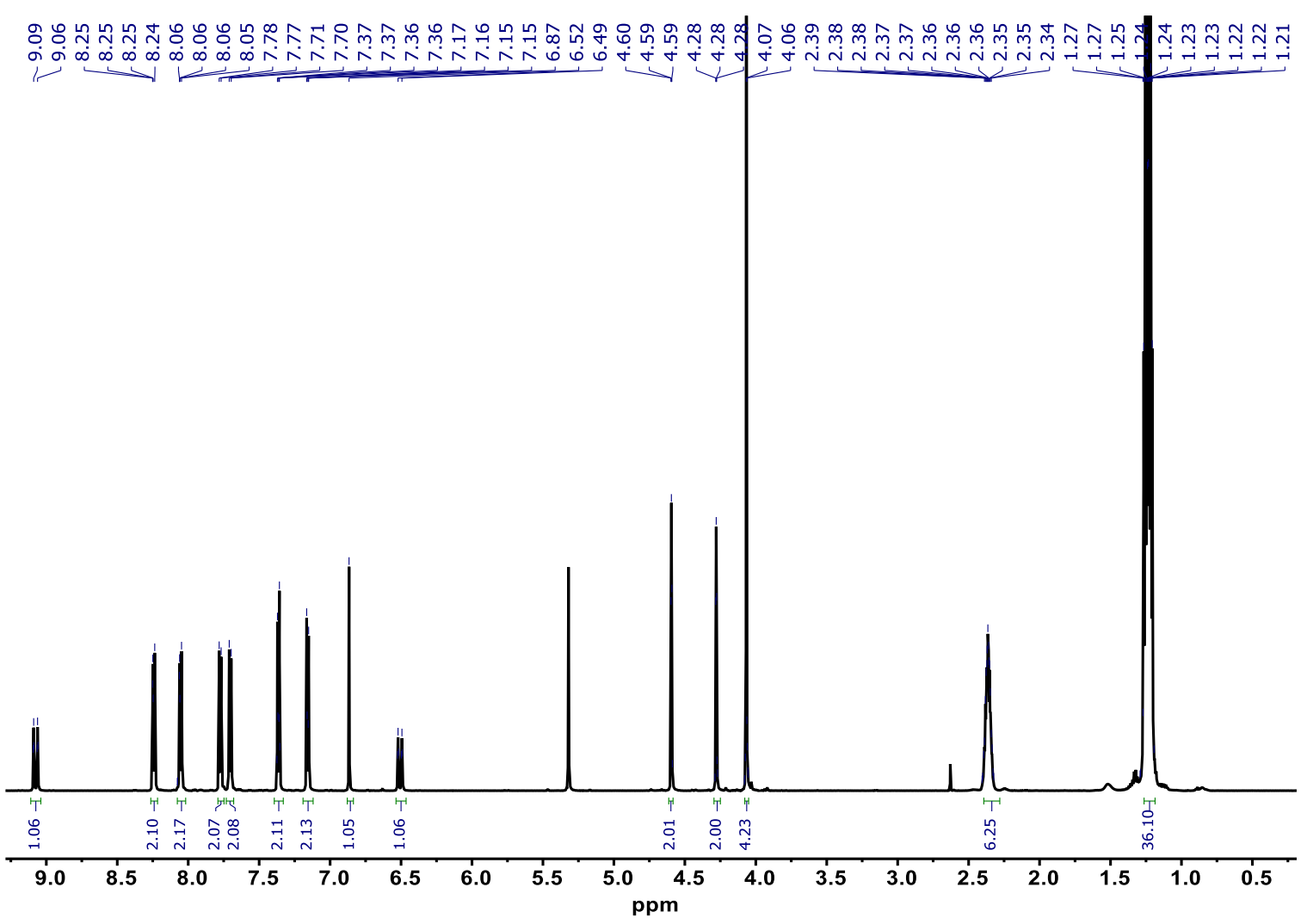

Figure S8. ${ }^{1} \mathrm{H}$ NMR spectrum of $\mathbf{2}-\mathbf{C F}_{3}$ in $\mathrm{CD}_{2} \mathrm{Cl}_{2}$ at room temperature.

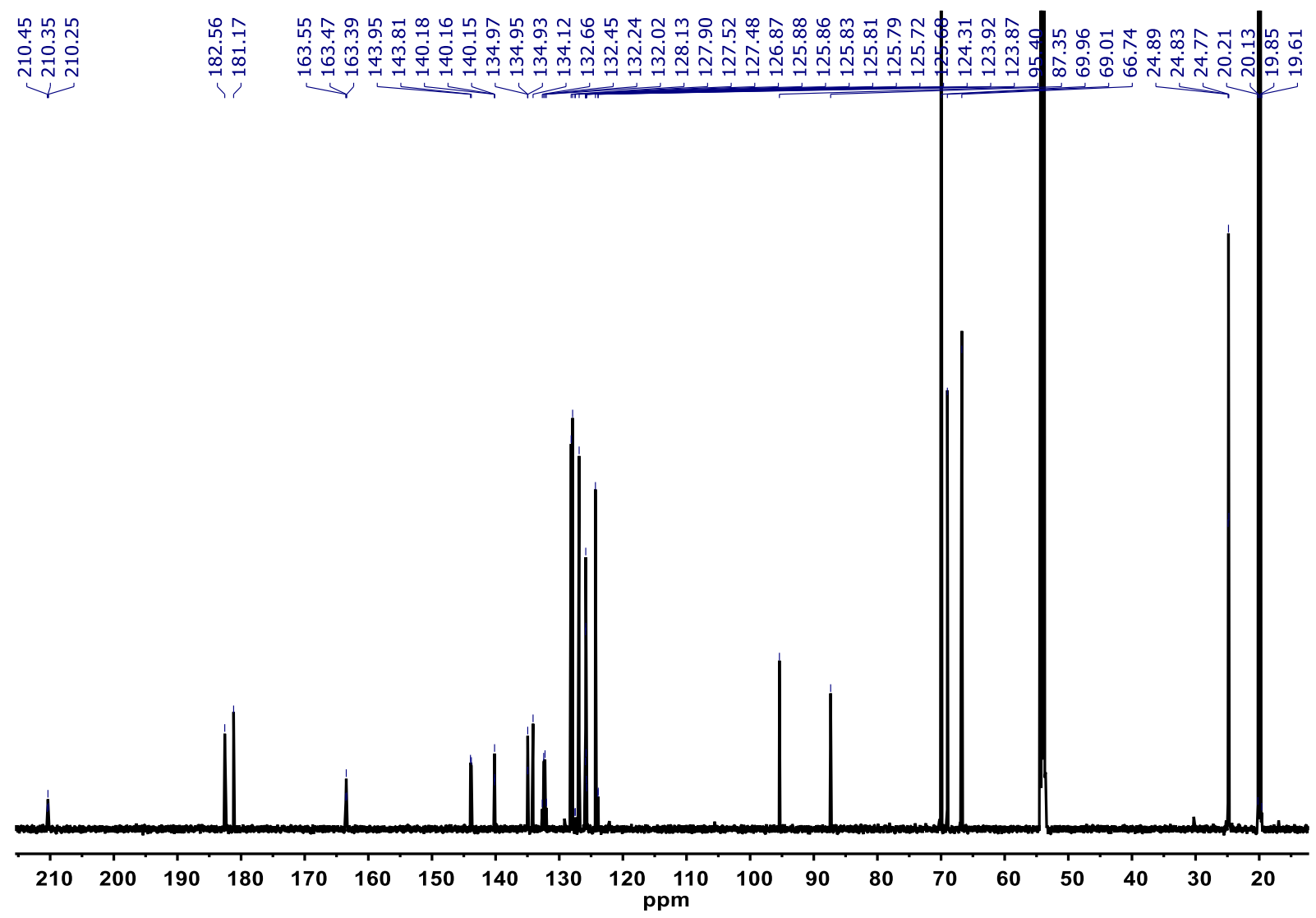

Figure S9. ${ }^{13} \mathrm{C}$ NMR spectrum of $\mathbf{2}-\mathrm{CF}_{3}$ in $\mathrm{CD}_{2} \mathrm{Cl}_{2}$ at room temperature. 


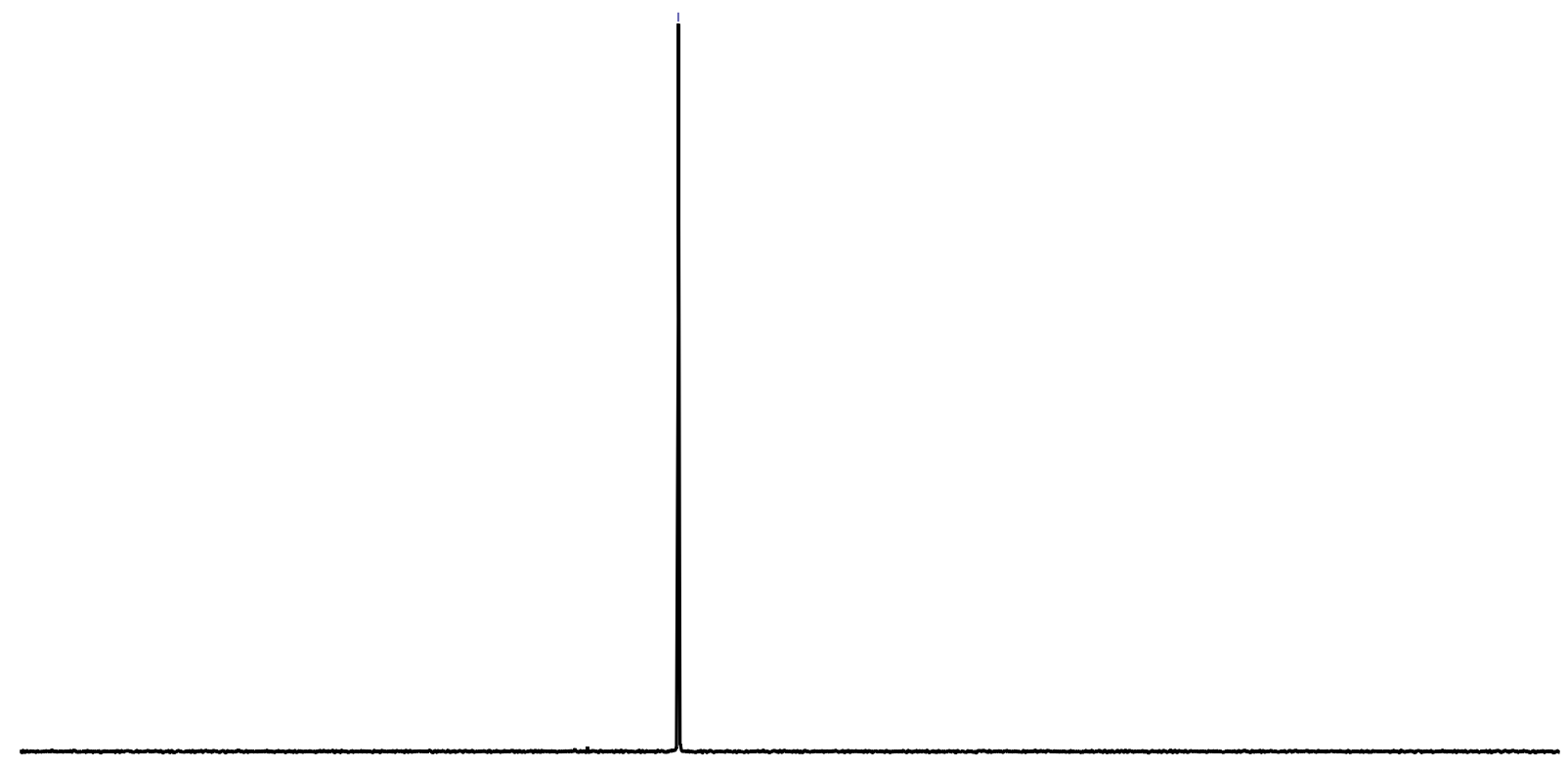

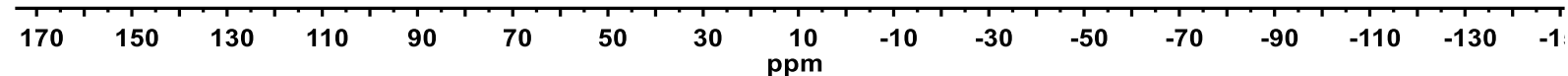

Figure S10. ${ }^{31} \mathrm{P}$ NMR spectrum of $2-\mathrm{CF}_{3}$ in $\mathrm{CD}_{2} \mathrm{Cl}_{2}$ at room temperature.

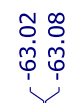
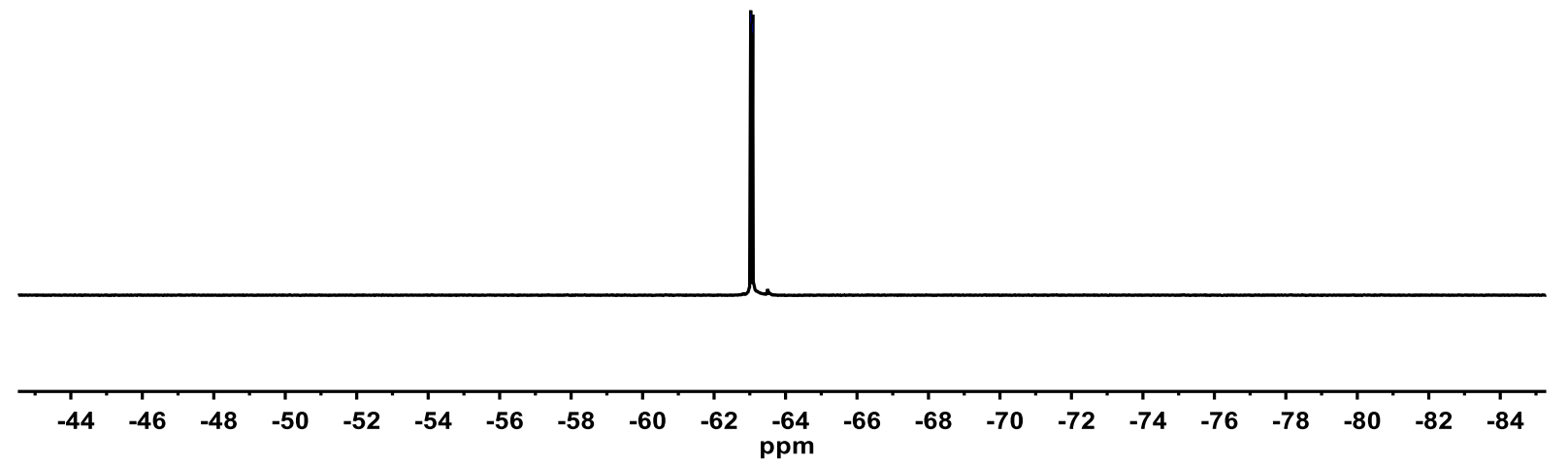

Figure $\mathrm{S} 11 .{ }^{19} \mathrm{~F}$ NMR spectrum of $2-\mathrm{CF}_{3}$ in $\mathrm{CD}_{2} \mathrm{Cl}_{2}$ at room temperature. 


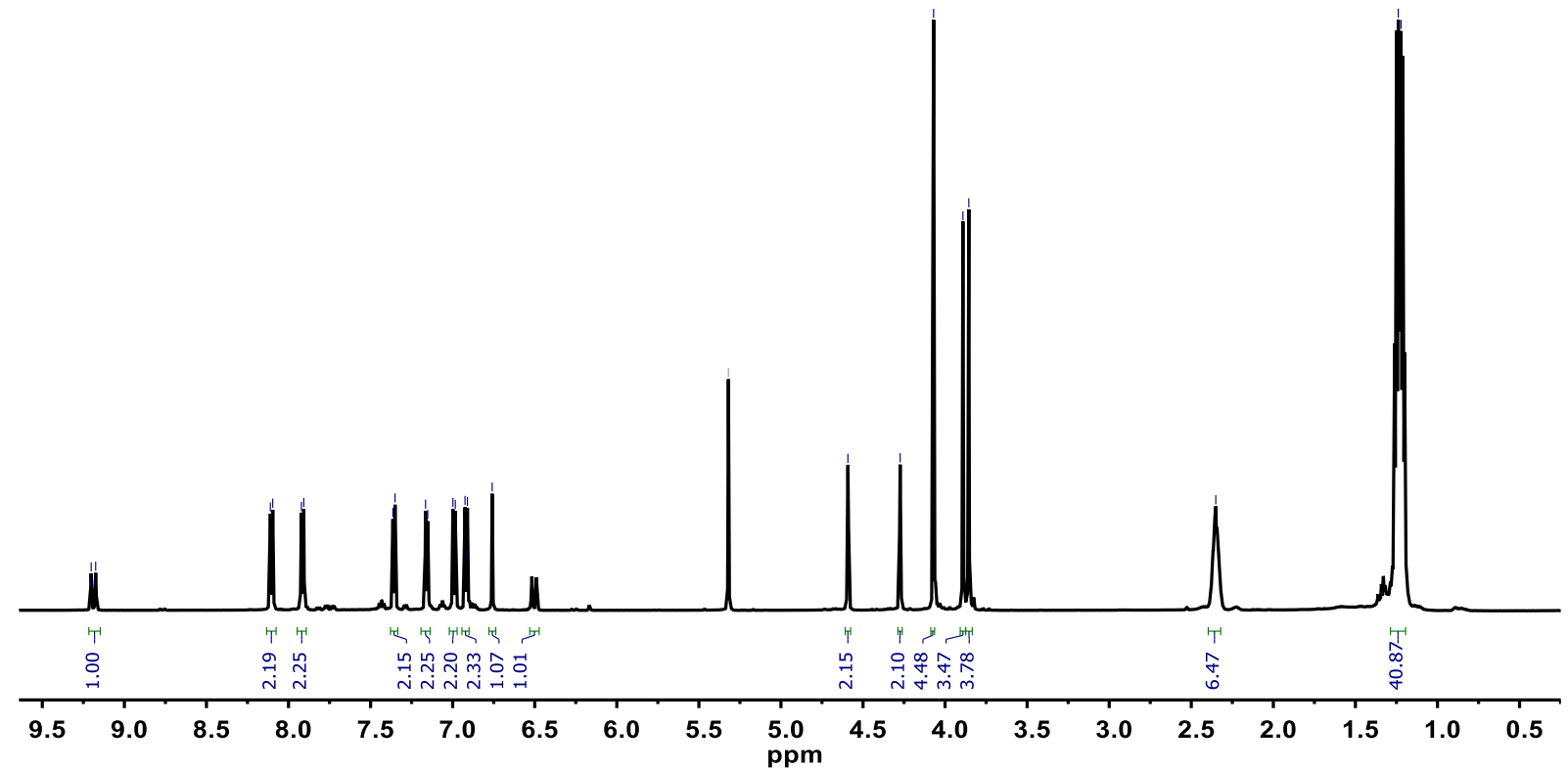

Figure $\mathrm{S} 12 .{ }^{1} \mathrm{H}$ NMR spectrum of $2-\mathrm{OMe}$ in $\mathrm{CD}_{2} \mathrm{Cl}_{2}$ at room temperature.

\section{œొ

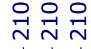

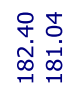

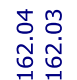

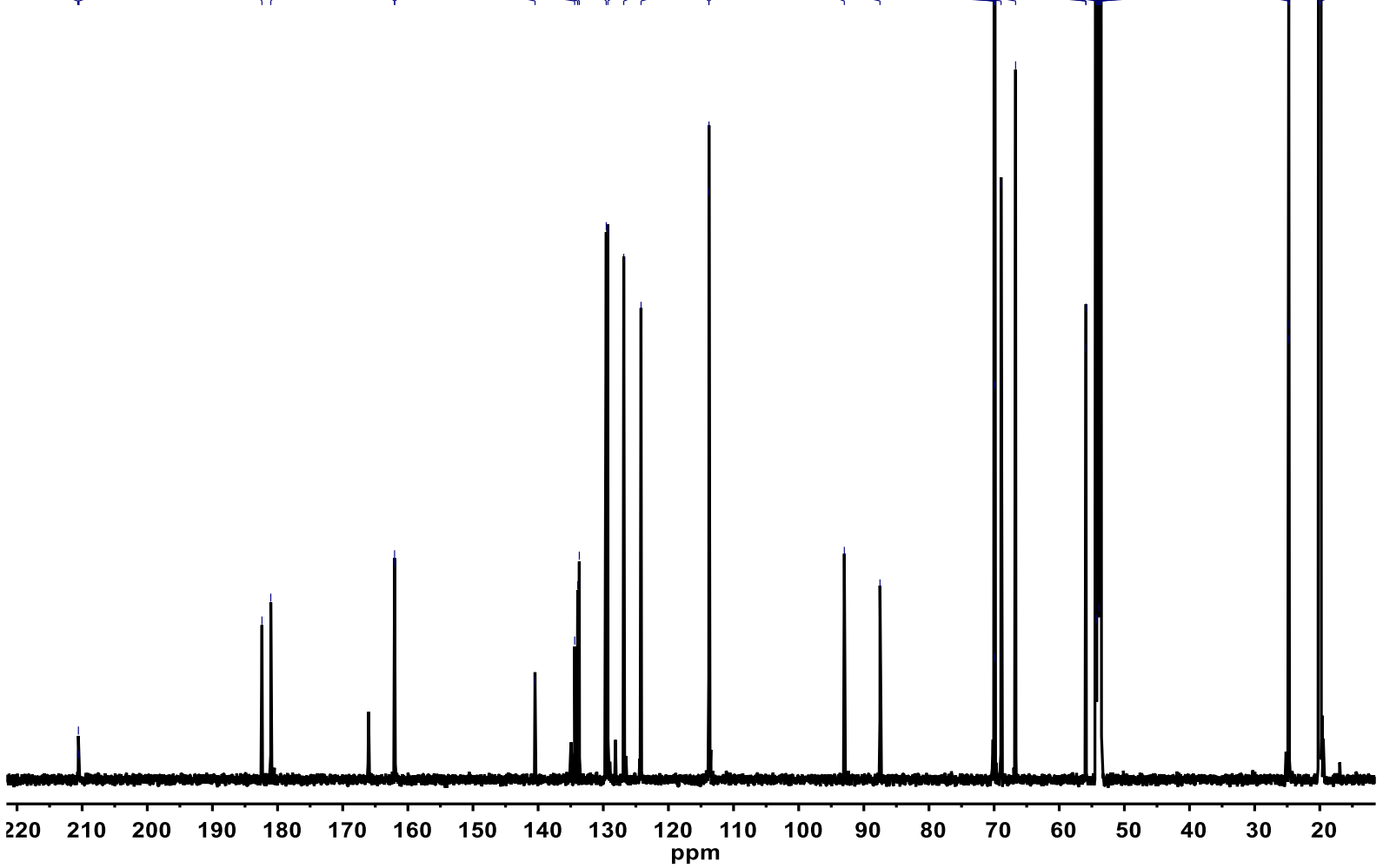

Figure $\mathrm{S} 13 .{ }^{13} \mathrm{C}$ NMR spectrum of 2-OMe in $\mathrm{CD}_{2} \mathrm{Cl}_{2}$ at room temperature. 


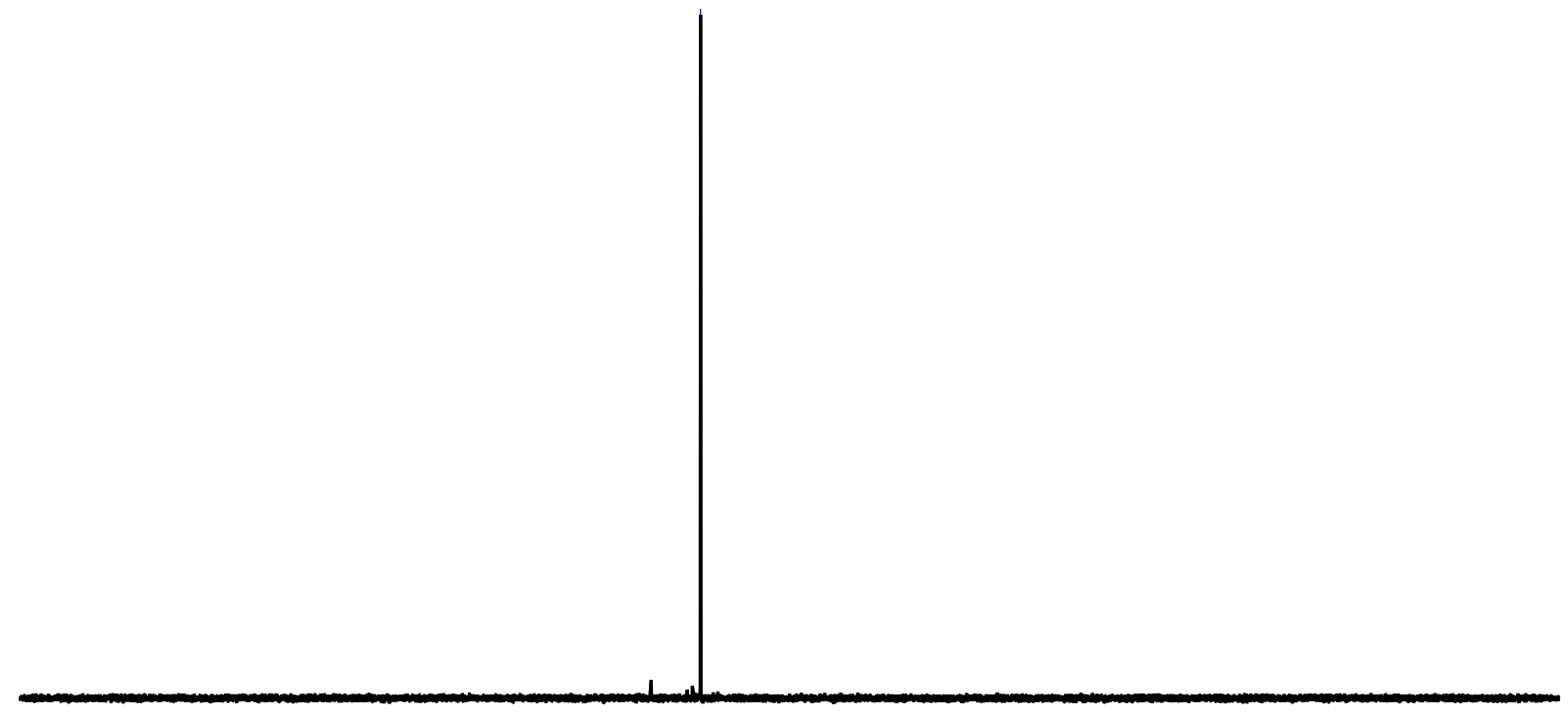

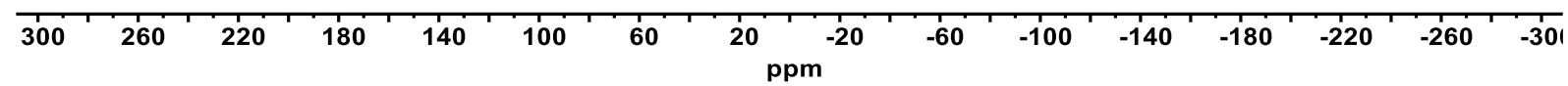

Figure $\mathrm{S} 14 .{ }^{31} \mathrm{P}$ NMR spectrum of 2-OMe in $\mathrm{CD}_{2} \mathrm{Cl}_{2}$ at room temperature. 


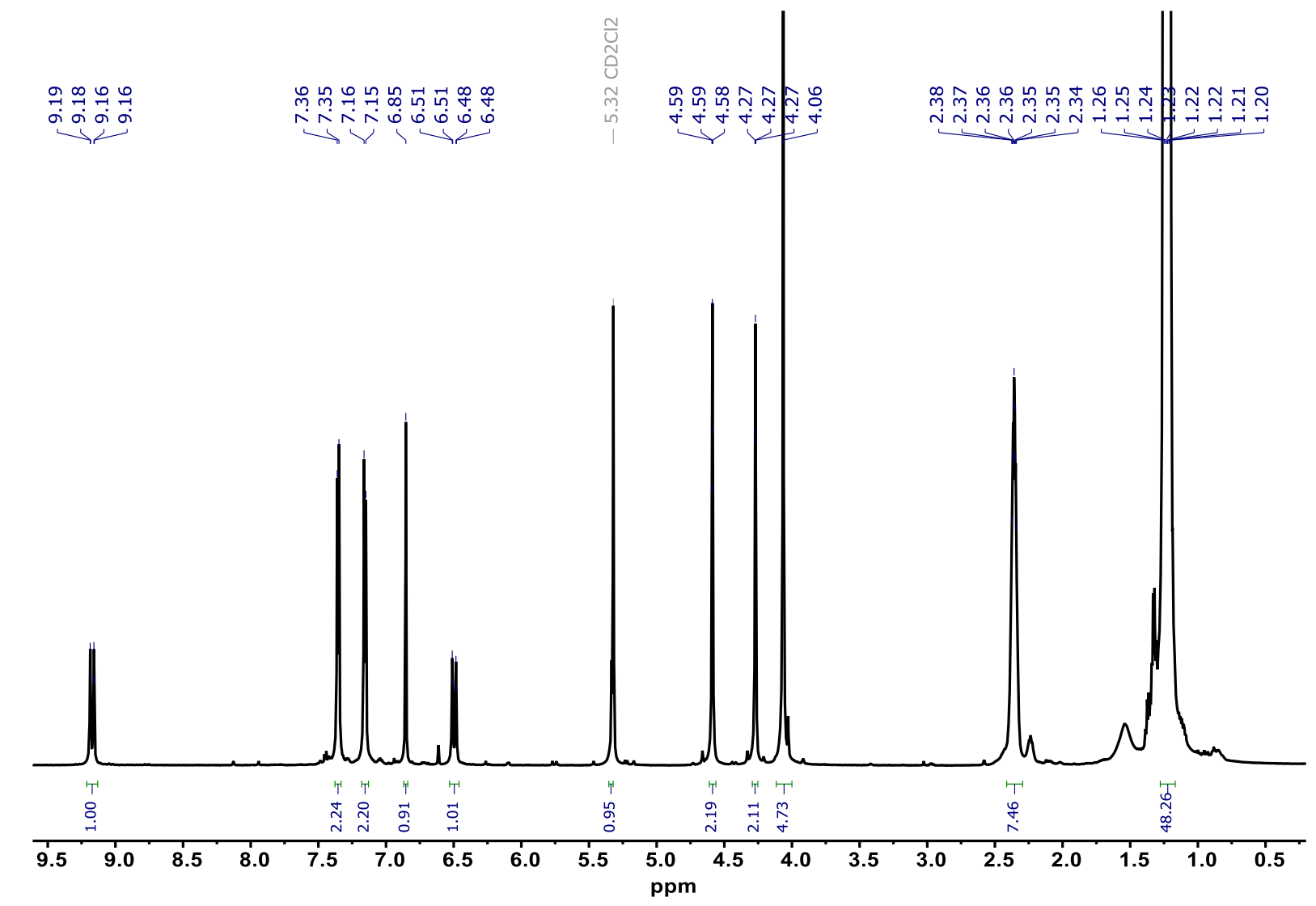

Figure S15. ${ }^{1} \mathrm{H}$ NMR spectrum of 2-D in $\mathrm{CD}_{2} \mathrm{Cl}_{2}$ at room temperature.

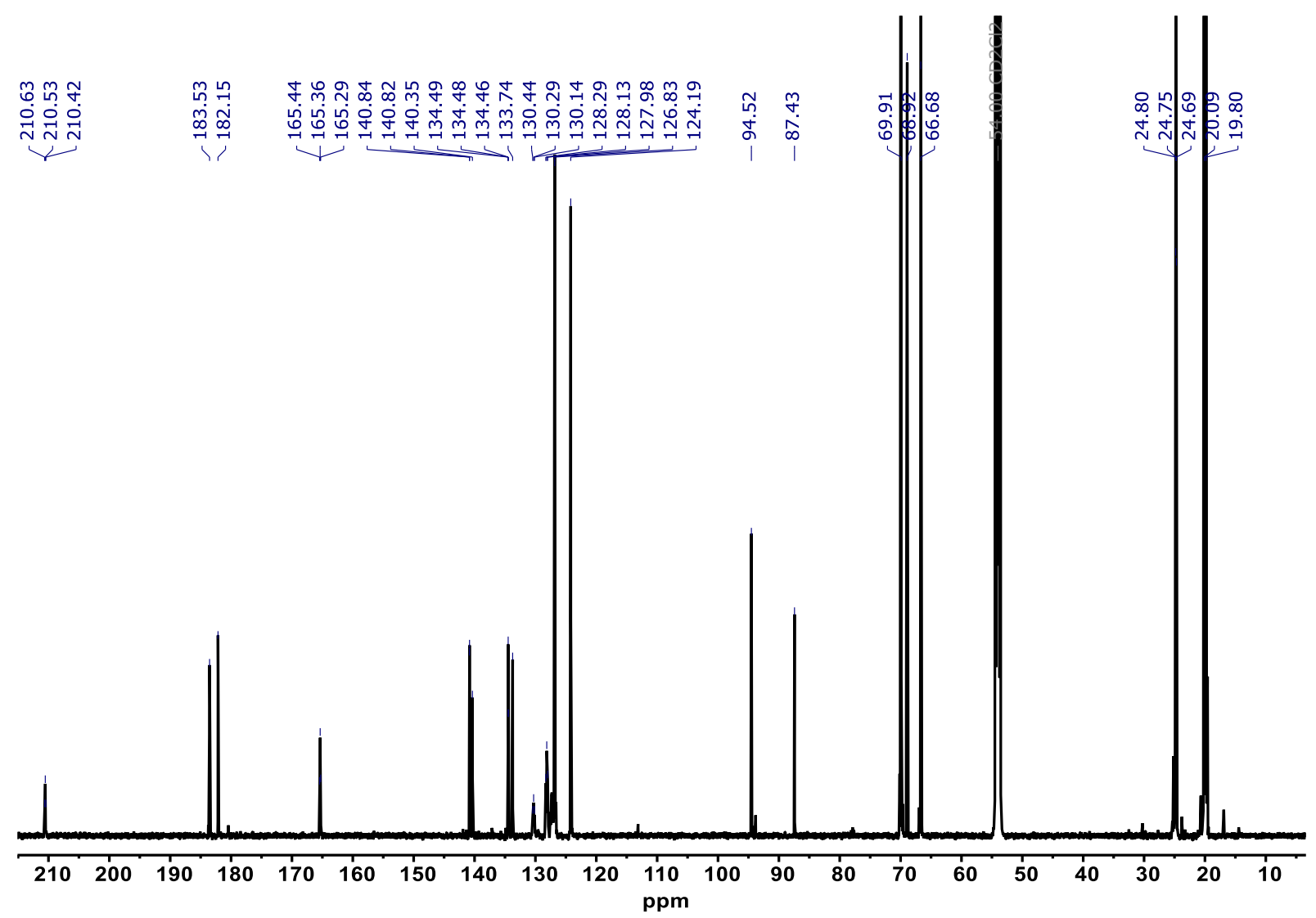

Figure $\mathrm{S} 16 .{ }^{13} \mathrm{C}$ NMR spectrum of 2-D in $\mathrm{CD}_{2} \mathrm{Cl}_{2}$ at room temperature. 


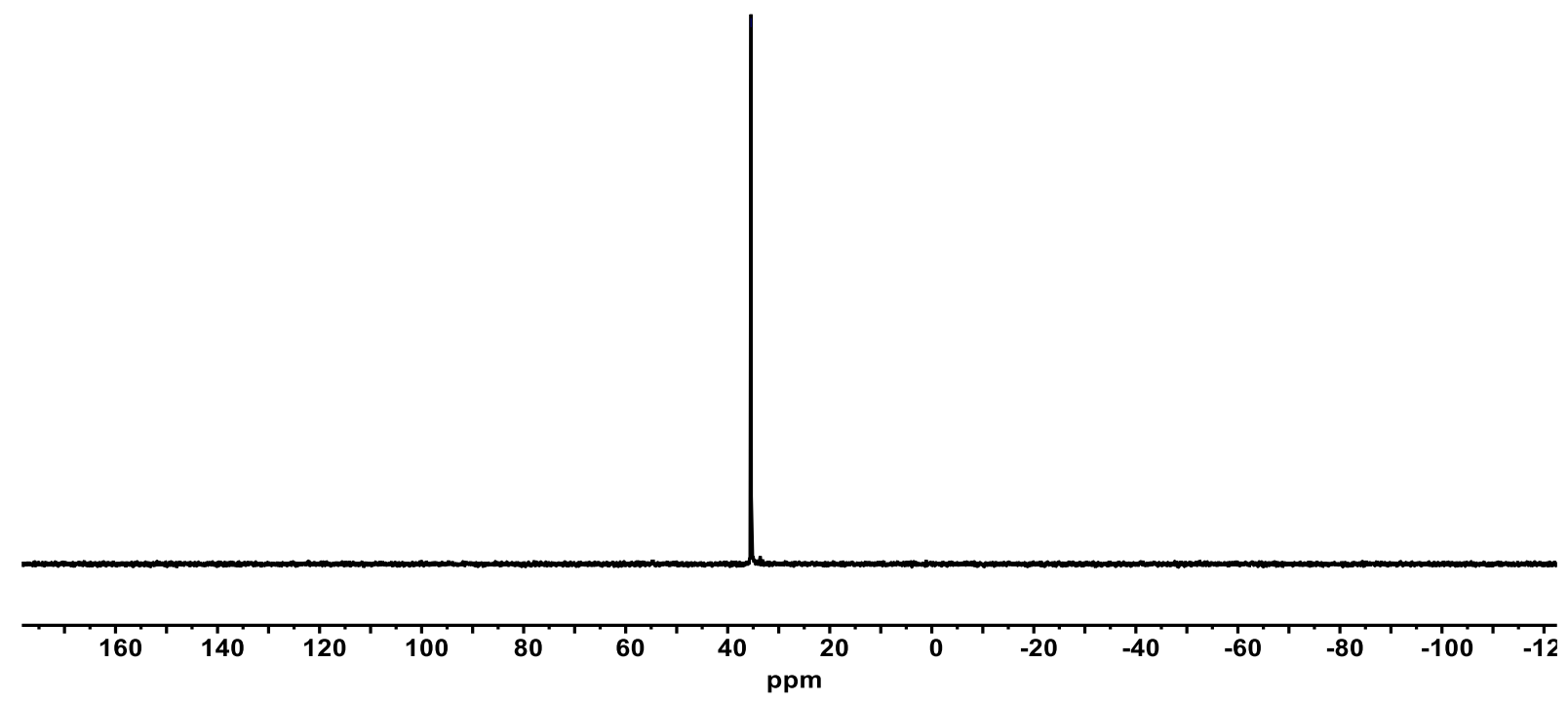

Figure S17. ${ }^{31} \mathrm{P}$ NMR spectrum of 2-D in $\mathrm{CD}_{2} \mathrm{Cl}_{2}$ at room temperature.

\section{X-ray diffraction study}

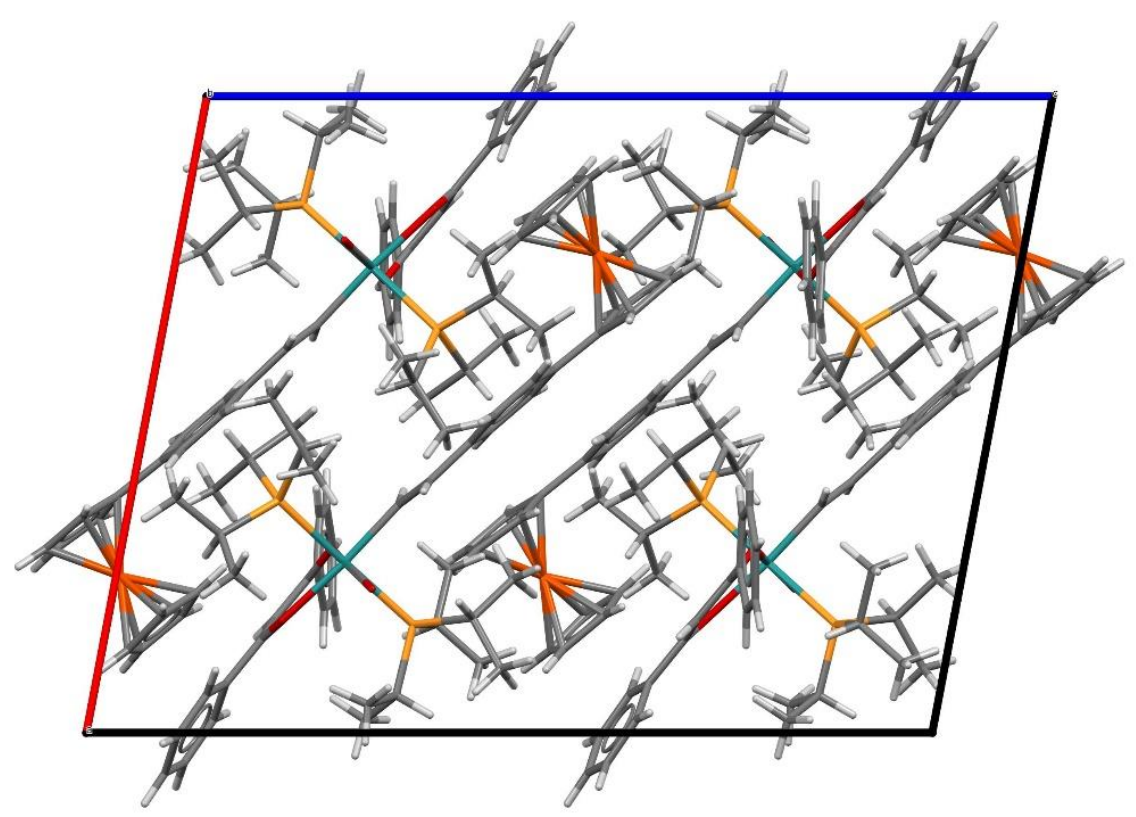

Figure S18. Packing of individual molecules in the crystal of complex 2-H. 


\section{Electrochemistry}

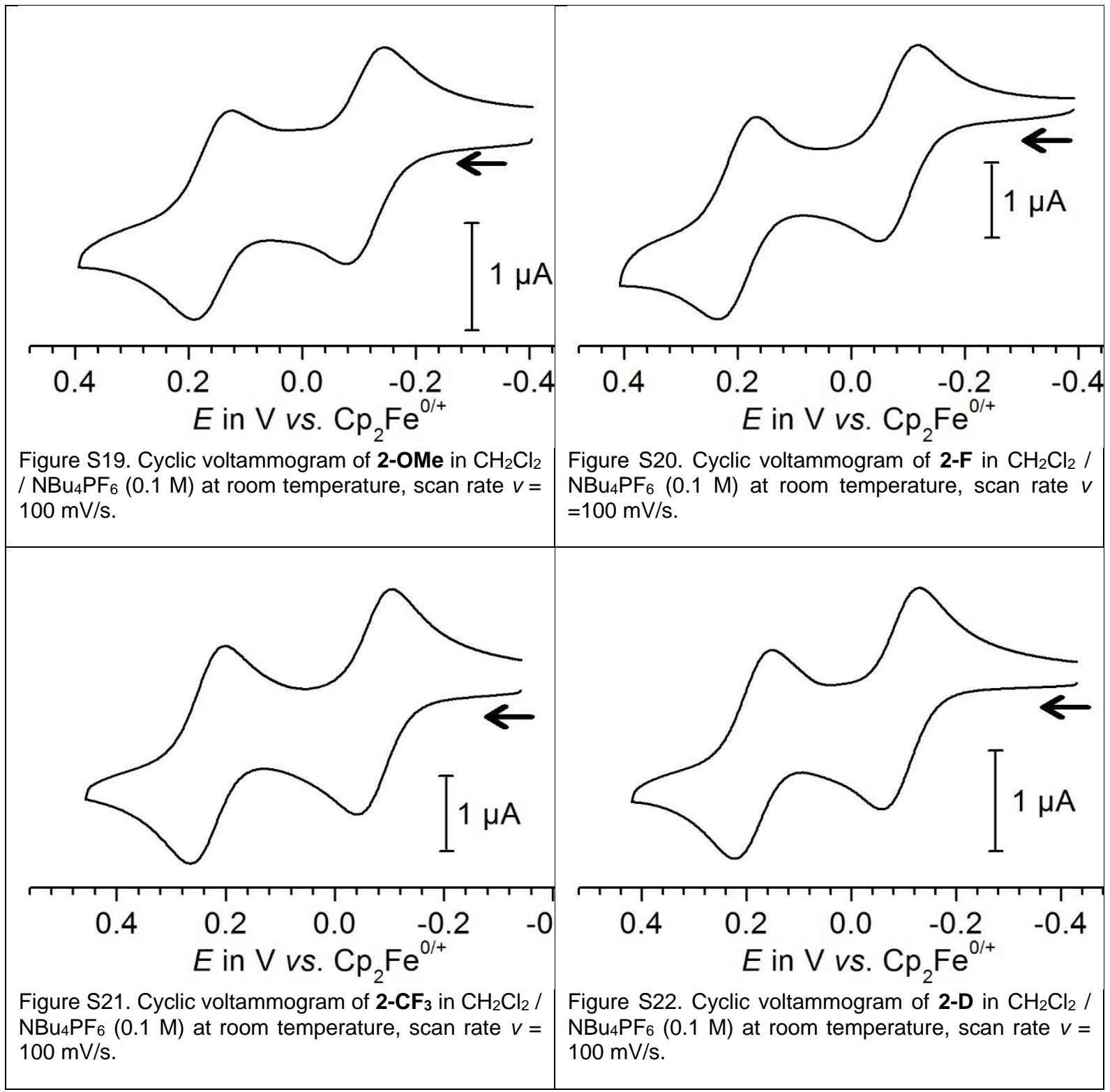




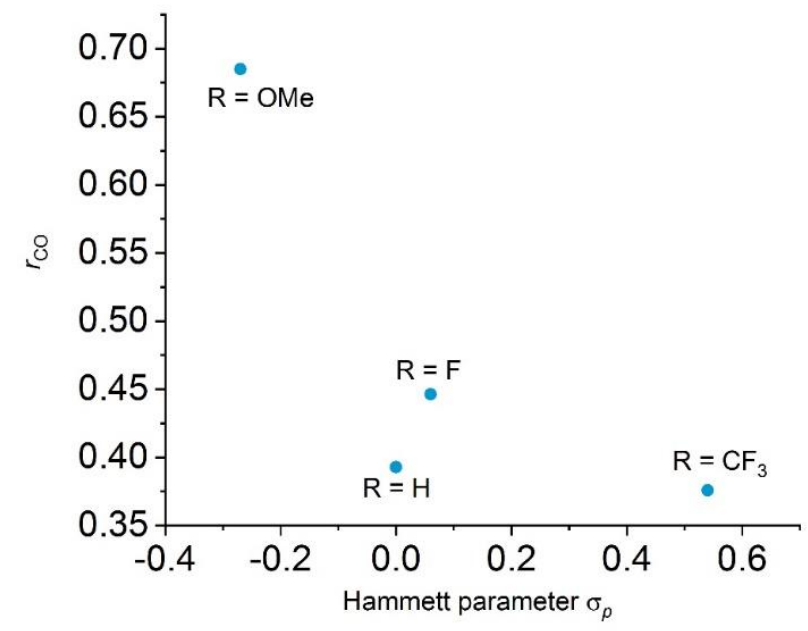

Figure S23. Plot of the $\sigma$-Hammett parameter of the substituents at the phenyl rings of the ketoenolato ligands versus rco.

\section{Quantum chemistry}

Table S1. Percentage of the MO coefficient contributions of the three complex entities to the HOMO of the neutral complexes calculated by population analysis $(6-31 \mathrm{G}(\mathrm{d}) / \mathrm{pbe} 1 \mathrm{pbe}$ level of theory).

\begin{tabular}{|c|c|c|c|}
\hline & $\mathrm{Ru}(\mathrm{CO}) \mathrm{Cl}\left(\mathrm{P}^{\mathrm{i} P \mathrm{P}_{3}}\right)_{2}(\mathrm{acac})$ & styryl & Fc \\
\hline 2-OMe & 37 & 54 & 9 \\
\hline 2-H & 36 & 54 & 10 \\
\hline $2-\mathrm{CF}_{3}$ & 32 & 55 & 13 \\
\hline
\end{tabular}



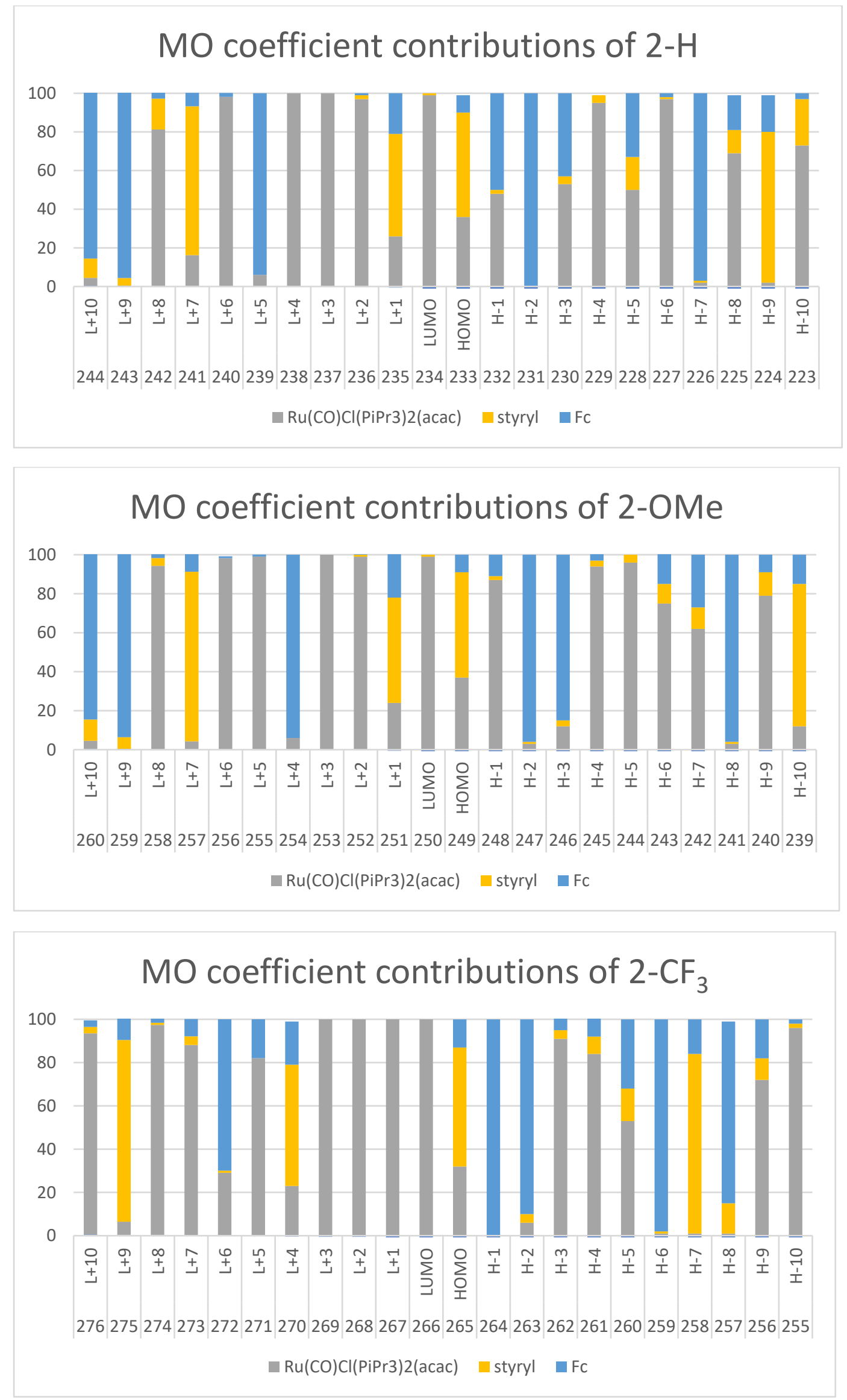

Figure S24. Compositions of MOs HOMO-10 to LUMO+10 for complexes $\mathbf{2 - H}, \mathbf{2}-\mathbf{O M e}$ and $\mathbf{2}-\mathbf{C F}_{3}$. 
Temperature- and solvent-dependence of the IR and NIR spectra
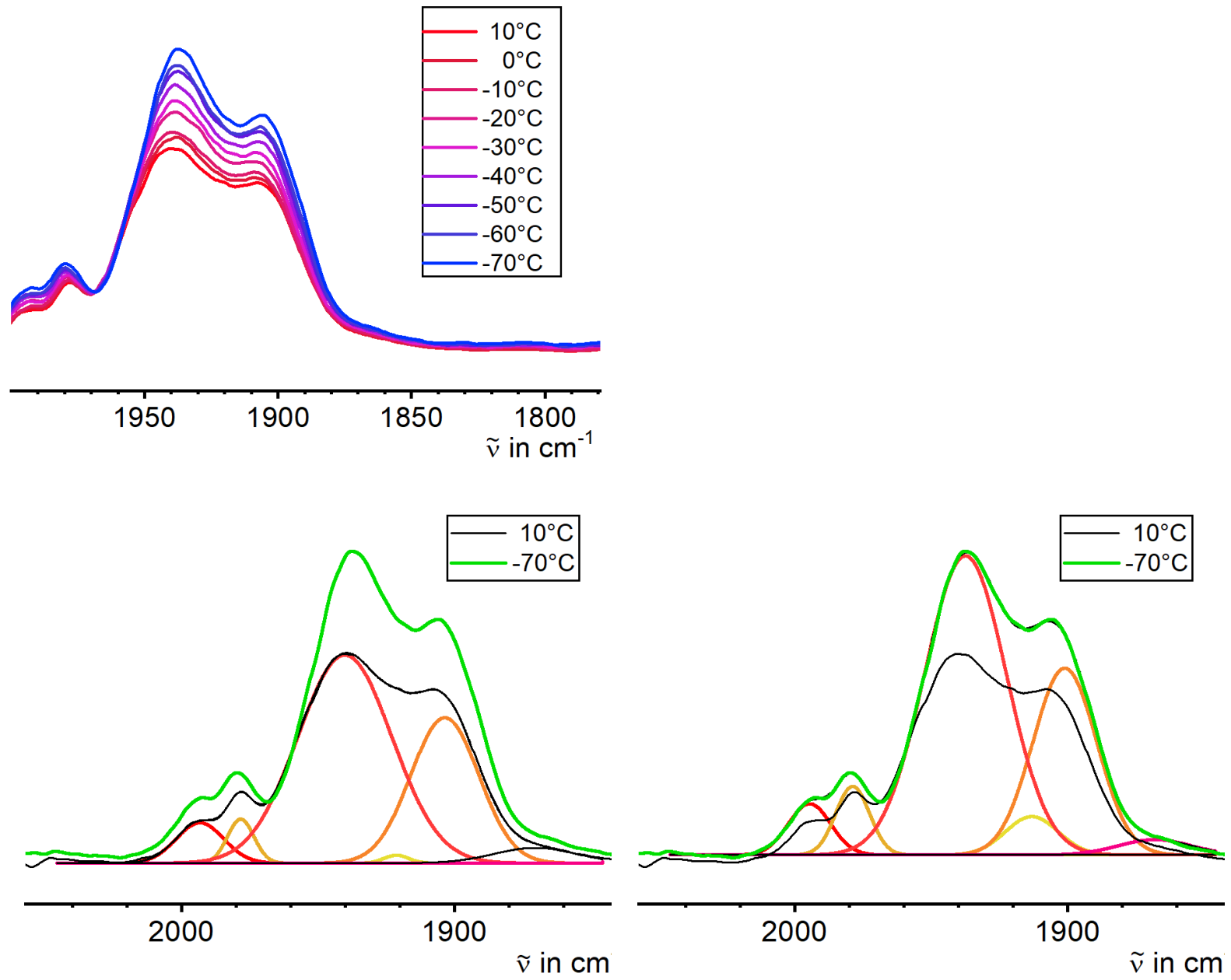

Figure S25. T-dependent IR spectra of $2-\mathrm{OMe}^{\bullet+}$ in the range of the $\mathrm{Ru}(\mathrm{CO})$ stretching vibrations over a temperature range of $+10^{\circ} \mathrm{C}$ to $-70^{\circ} \mathrm{C}$ (top). Deconvolution of the spectrum at $T=10^{\circ} \mathrm{C}$ (left) and $T=-70^{\circ} \mathrm{C}$ (right). 

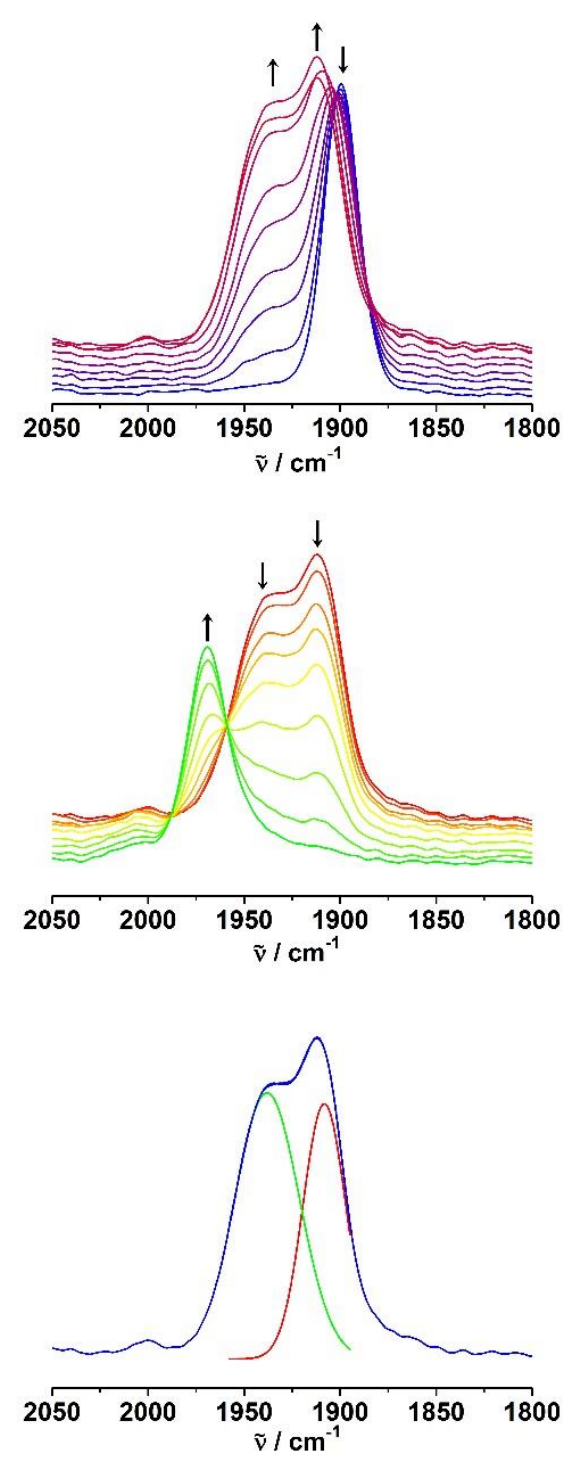
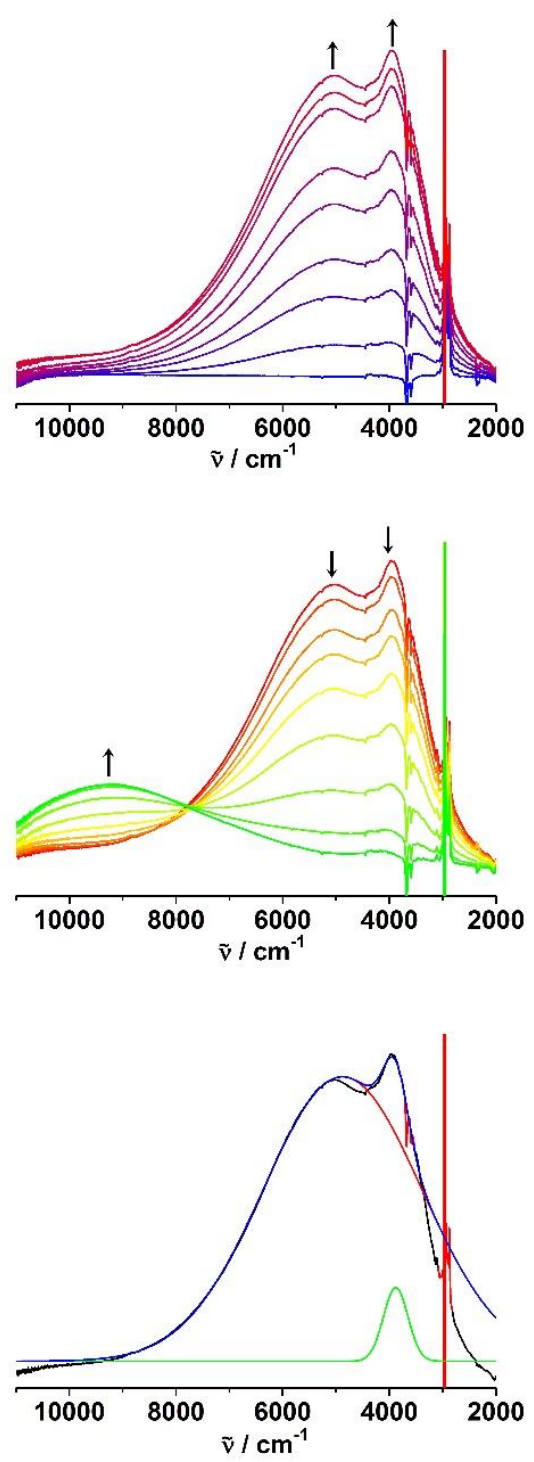

Figure S26. IR and NIR spectroelectrochemistry of 2-H in 1,2-dichloroethane/NBu $4 \mathrm{PF}_{6}(0.1 \mathrm{M})$ at room temperature and the deconvolution of the two-band pattern in the IR and NIR regions. Top and middle panel: blue $=$ neutral, red $=$ radical cation, green $=$ dication. Bottom: Red and green lines represent the two Gaussians and the blue line their sum; the black line represents the experimental spectrum. 

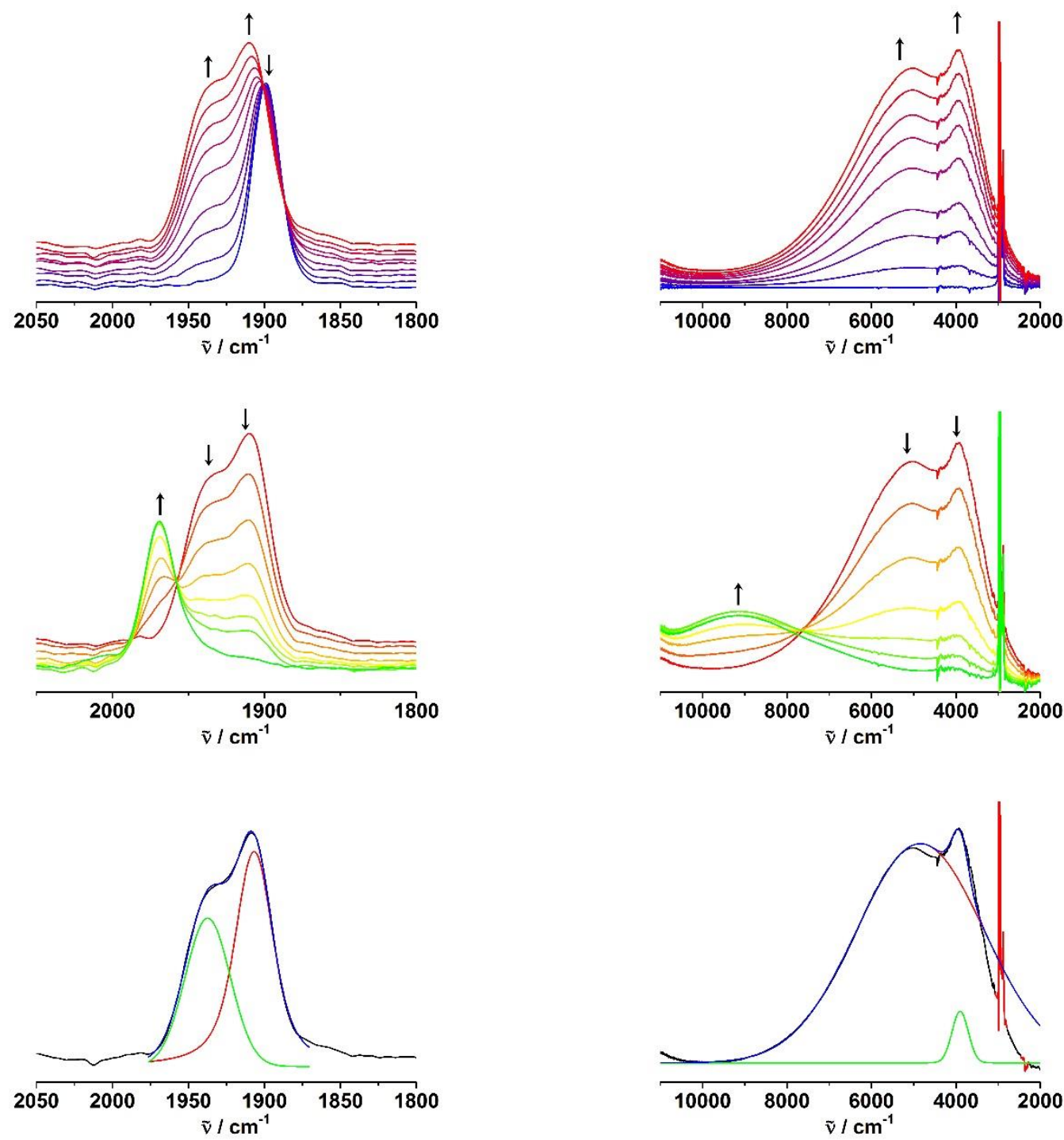

Figure S27. IR and NIR spectroelectrochemistry of 2-D in 1,2-dichloroethane/NBu4PF $6(0.1 \mathrm{M})$ at room temperature and the deconvolution of the two-band pattern in the IR and NIR region. Top and middle panel: blue = neutral, red $=$ radical cation, green = dication. Bottom: Red and green lines represent the two Gaussians and the blue line their sum; the black line represents the experimental spectrum. 

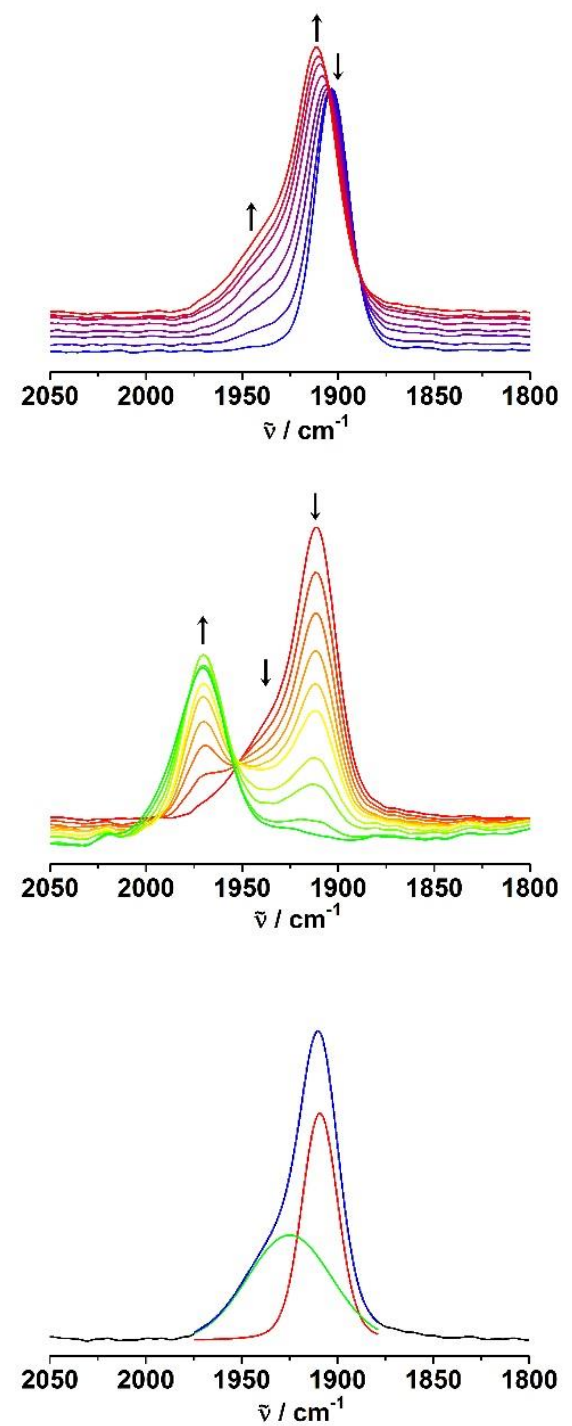
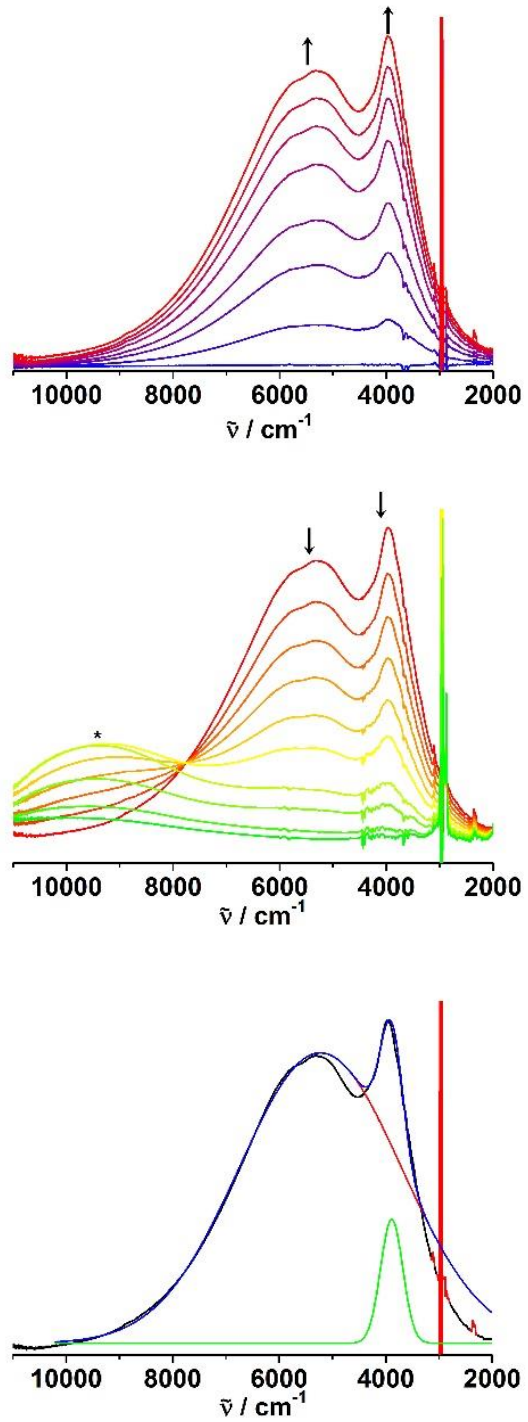

Figure S28. IR and NIR spectroelectrochemistry of $2-\mathrm{CF}_{3}$ in 1,2 -dichloroethane/NBu4 $\mathrm{PF}_{6}(0.1 \mathrm{M})$ at room temperature and the deconvolution of the two-band pattern in the IR and NIR region. Top and middle panel: blue = neutral, red = radical cation, green = dication. Bottom: Red and green lines represent the two Gaussians and the blue line their sum; the black line represents the experimental spectrum. 

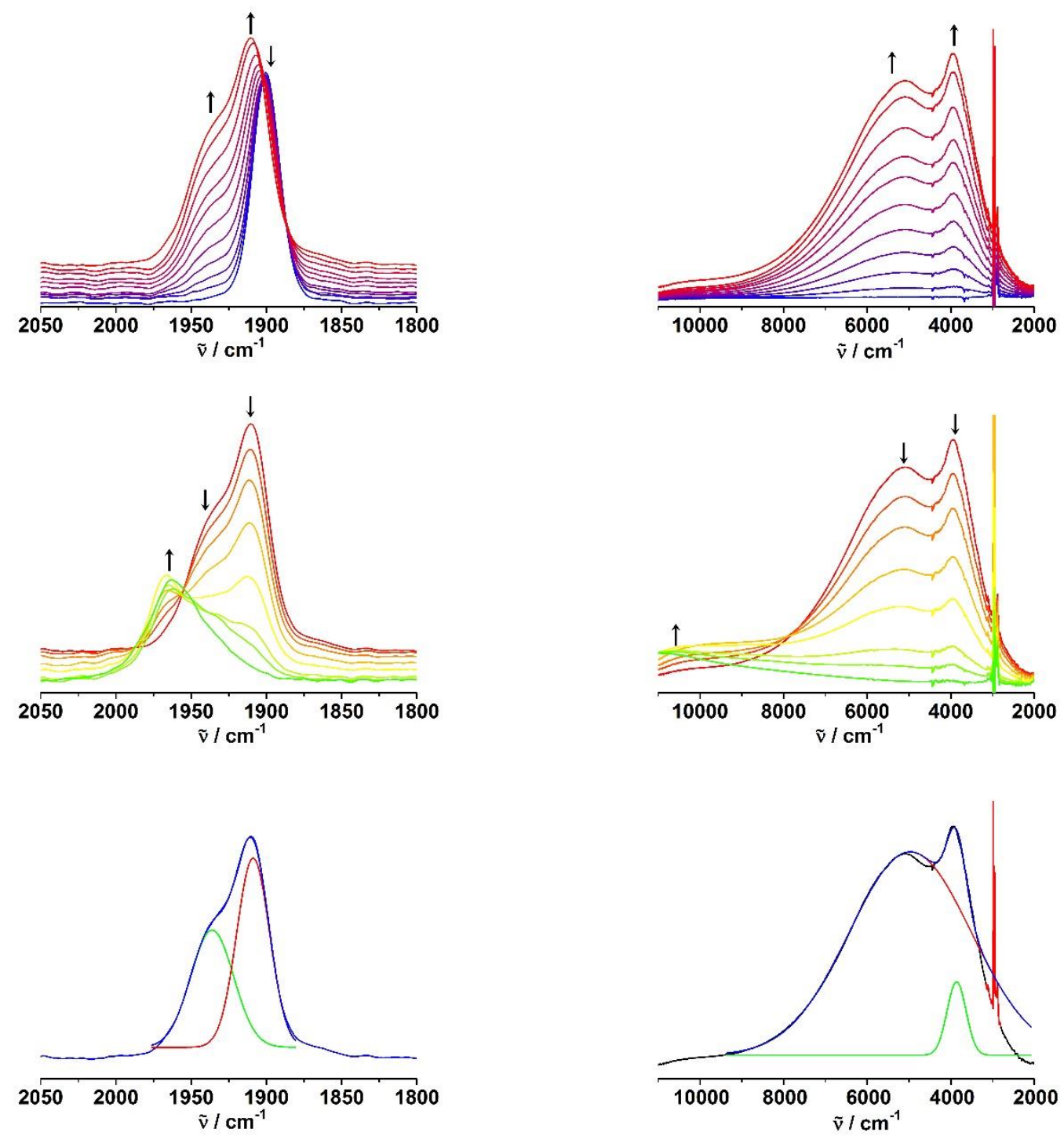

Figure S29. IR and NIR spectroelectrochemistry of 2-F in 1,2-dichloroethane/NBu $\mathrm{PF}_{6}(0.1 \mathrm{M})$ at room temperature and the deconvolution of the two-band pattern in the IR and NIR region. Top and middle panel: blue = neutral, red $=$ radical cation, green = dication. Bottom: Red and green lines represent the two Gaussians and the blue line their sum; the black line represents the experimental spectrum. 

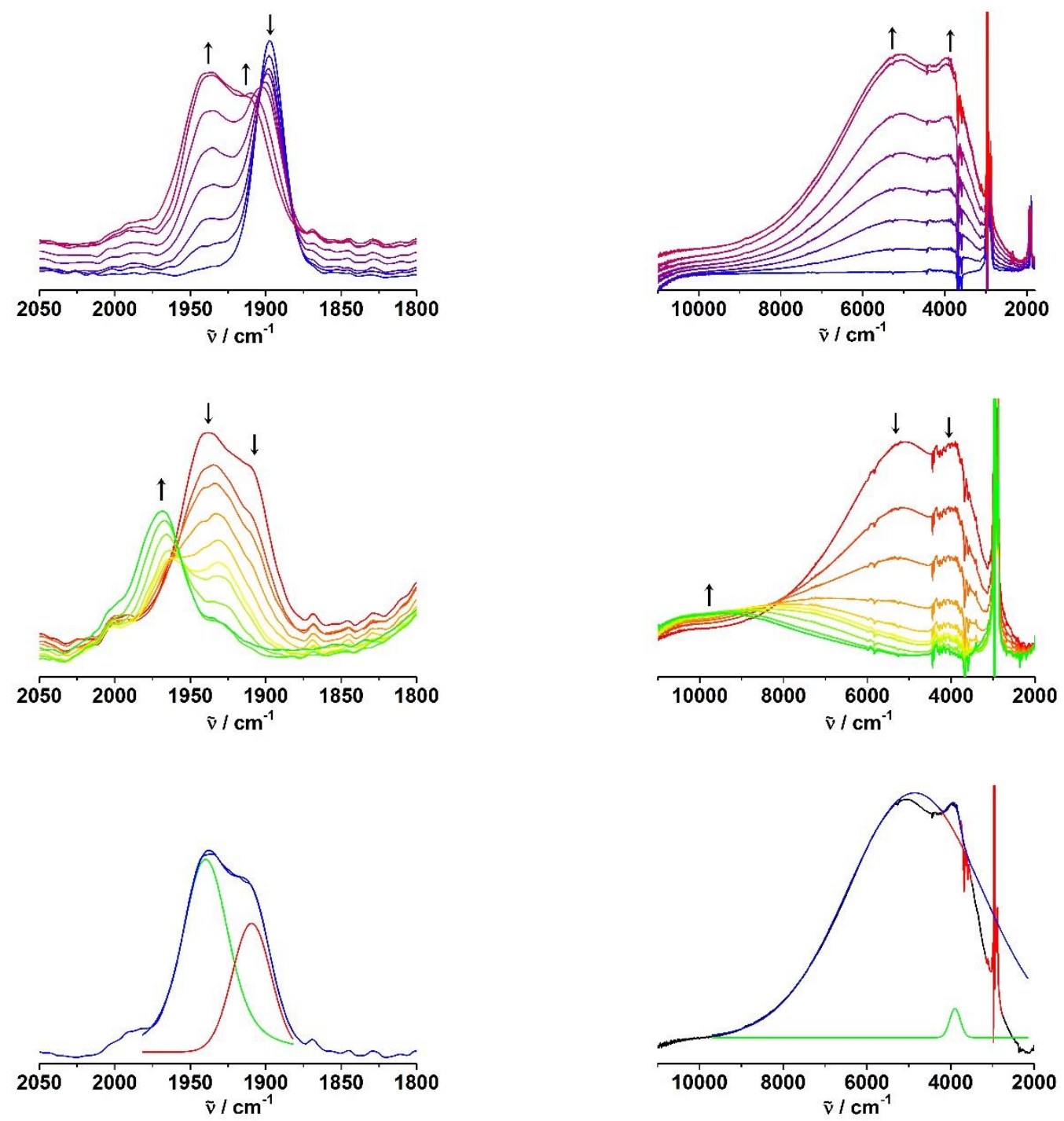

Figure S30. IR and NIR spectroelectrochemistry of 2-OMe in 1,2-dichloroethane/NBu $4 \mathrm{PF}_{6}(0.1 \mathrm{M})$ at room temperature and the deconvolution of the two-band pattern in the IR and NIR region. Top and middle panel: blue = neutral, red = radical cation, green = dication. Bottom: Red and green lines represent the two Gaussians and the blue line their sum; the black line represents the experimental spectrum. 


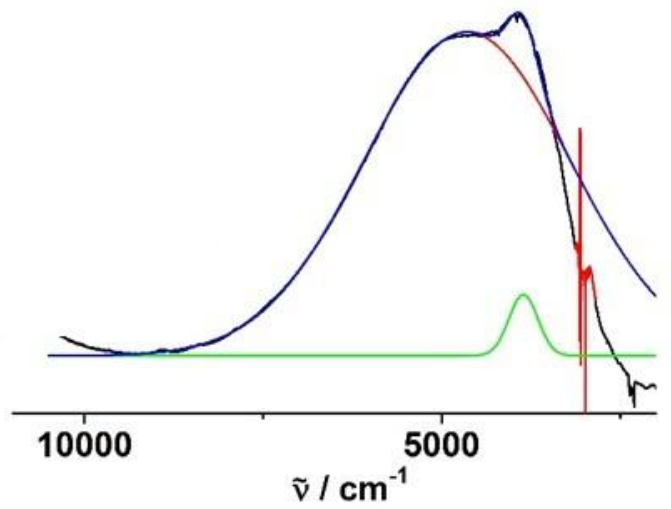

Figure S31. NIR spectrum of the $\left[\mathrm{B}\left\{\mathrm{C}_{6} \mathrm{H}_{3}\left(\mathrm{CF}_{3}\right)_{2}-3,5\right\}\right]^{-}$salt of cation 2-OMe+ in dichloromethane.

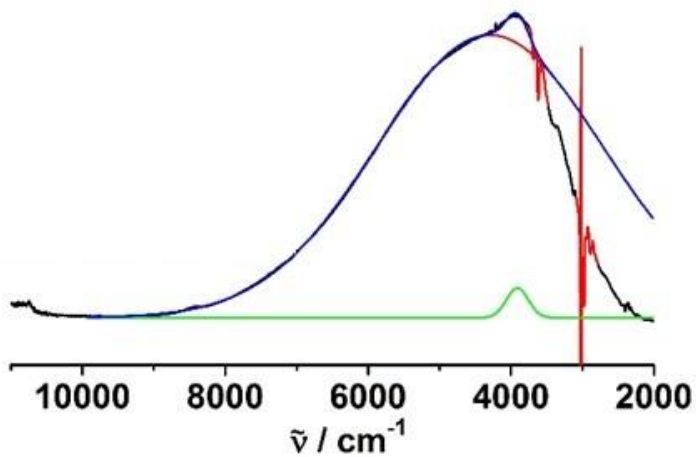

Figure S32. NIR spectrum of the $\left[\mathrm{B}\left\{\mathrm{C}_{6} \mathrm{H}_{3}\left(\mathrm{CF}_{3}\right)_{2}-3,5\right\}\right]^{-}$salt of cation 2-OMe ${ }^{+}$in chloroform with deconvolution.

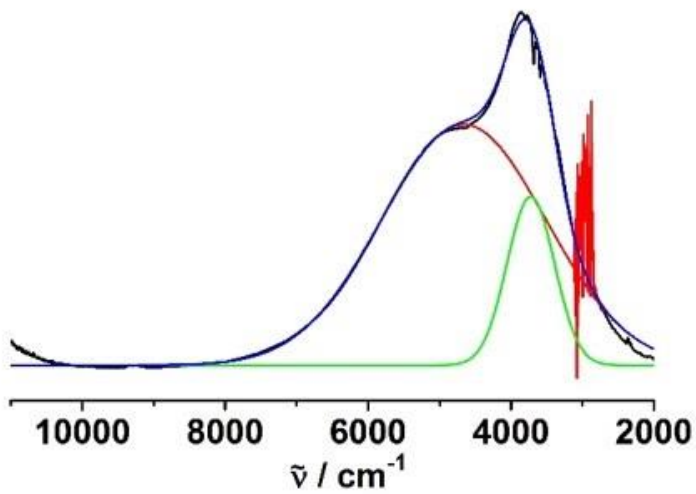

Figure S33. NIR spectrum of the $\left[\mathrm{B}\left\{\mathrm{C}_{6} \mathrm{H}_{3}\left(\mathrm{CF}_{3}\right)_{2}-3,5\right\}\right]^{-}$salt of cation 2-OMe+ in toluene with deconvolution. 


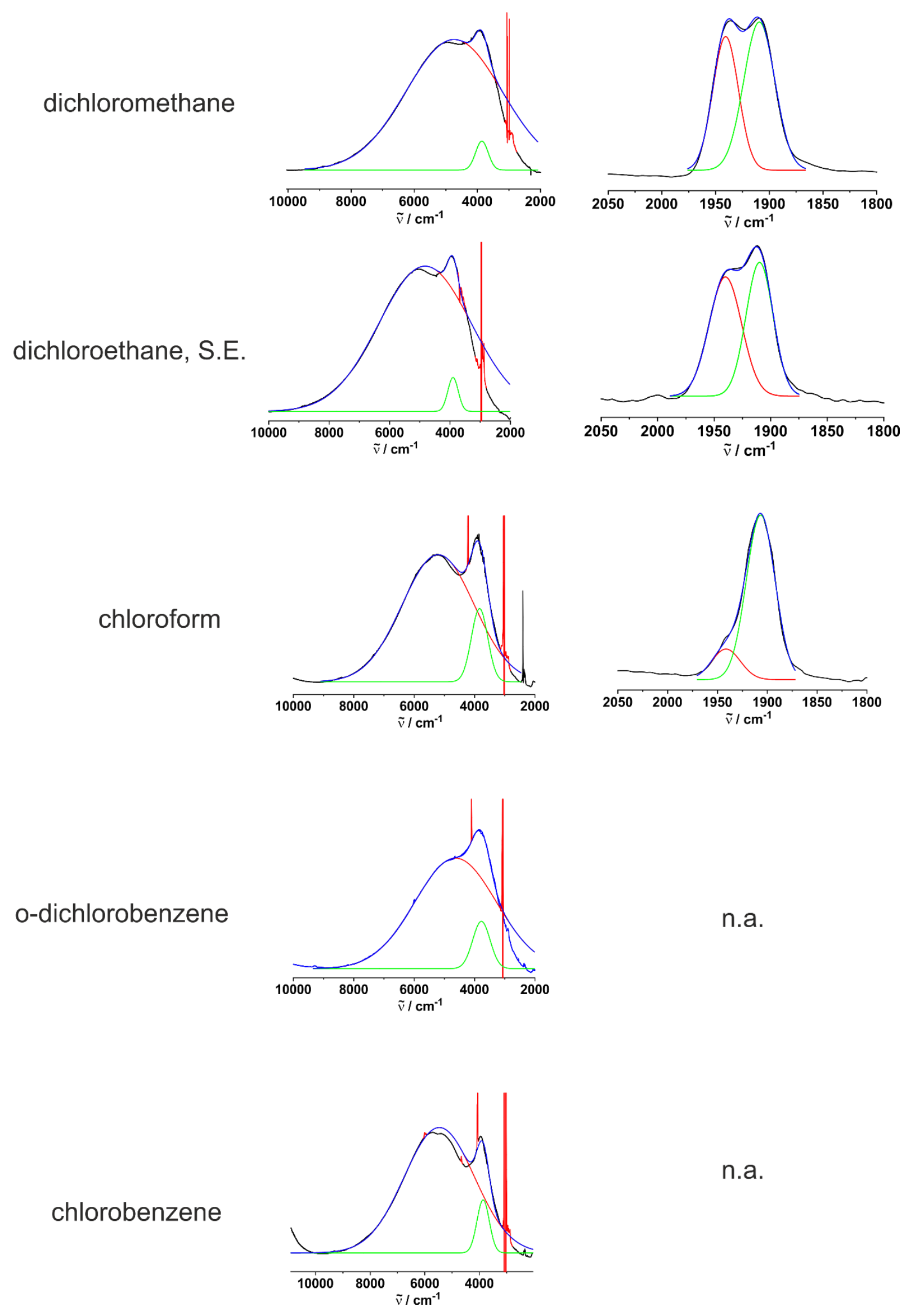

Figure S34. Study of the solvatochromism of $2-\mathrm{H}^{+}$. NIR and IR spectra in the region of the CO-stretching vibrations with deconvolutions. 


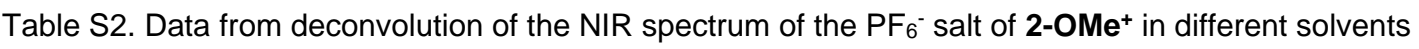

\begin{tabular}{l|l|l|l} 
Solvent & $\begin{array}{l}\text { FWHM high } \\
\text { energy }\end{array}$ & $\begin{array}{l}\text { FWHM } \\
\text { low energy }\end{array}$ & $\begin{array}{l}\text { dielectric } \\
\text { constant }\end{array}$ \\
\hline chloroform & 2809 & 638 & 4.81 \\
\hline chlorobenzene & 3033 & 531 & 5.62 \\
\hline dichloromethane & 3567 & 469 & 8.93 \\
\hline o-dichlorobenzene & 3164 & 678 & 9.93 \\
\hline dichloroethane, S.El. & 3601 & 405 & 10.36
\end{tabular}

Table S3. Data from deconvolution of the NIR spectrum of the $\left[\mathrm{B}\left\{\mathrm{C}_{6} \mathrm{H}_{3}\left(\mathrm{CF}_{3}\right)_{2}-3,5\right\}\right]^{--}$salt of $2-\mathbf{O M e}^{+}$in different solvents (FWHM = full-width at half-height)

\begin{tabular}{l|l|l|l} 
Solvent & $\begin{array}{l}\text { FWHM high } \\
\text { energy }\end{array}$ & $\begin{array}{l}\text { FWHM } \\
\text { low energy }\end{array}$ & $\begin{array}{l}\text { dielectric } \\
\text { constant }\end{array}$ \\
\hline toluene & 2703 & 781 & 2.38 \\
\hline OEt2 & 3168 & 590 & 4.33 \\
\hline chloroform & 3717 & 363 & 4.81 \\
\hline chlorobenzene & 3353 & 606 & 5.62 \\
\hline dichloromethane & 3383 & 477 & 8.93 \\
\hline o-dichlorobenzene & 3456 & 543 & 9.93
\end{tabular}

Table S4. $r_{\mathrm{CO}}$ and NIR solvatochromism of $\mathbf{2}-\mathrm{H}^{+}\left(r_{\mathrm{CO}}=\right.$ ratio of the peak area of the $\mathrm{CO}$ band at the higher energy to the total $\mathrm{CO}$ band intensities as defined by eq. 1.)

\begin{tabular}{l|l|c} 
solvent & $\boldsymbol{r}_{c o}$ & Energy of the NIR bands [ $\left.\mathbf{c m}^{-1}\right]$ \\
\hline dichloromethane & 0.40 & $4738+3857$ \\
\hline chloroform & 0.16 & $5205+3835$ \\
\hline dichloroethane, S.E. & 0.52 & $4823+3899$ \\
\hline chlorobenzene & n.a. & $5467+3861$ \\
\hline o-dichlorobenzene & n.a. & $4629+3774$
\end{tabular}




\section{UV/Vis/NIR spectroelectrochemistry}
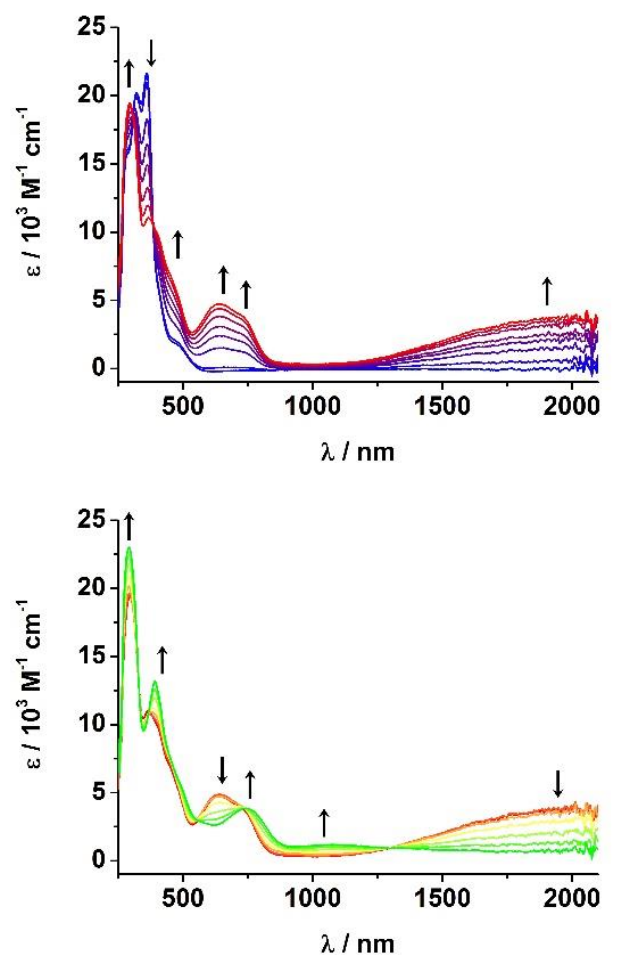

Figure S35. UV/vis/NIR spectroelectrochemistry of complex 2-H in 1,2-dichloroethane/ $\mathrm{NBu}_{4} \mathrm{PF}_{6}(0.1 \mathrm{M})$ at room temperature (blue line = neutral complex, red line = radical cation, green line $=$ dication). 

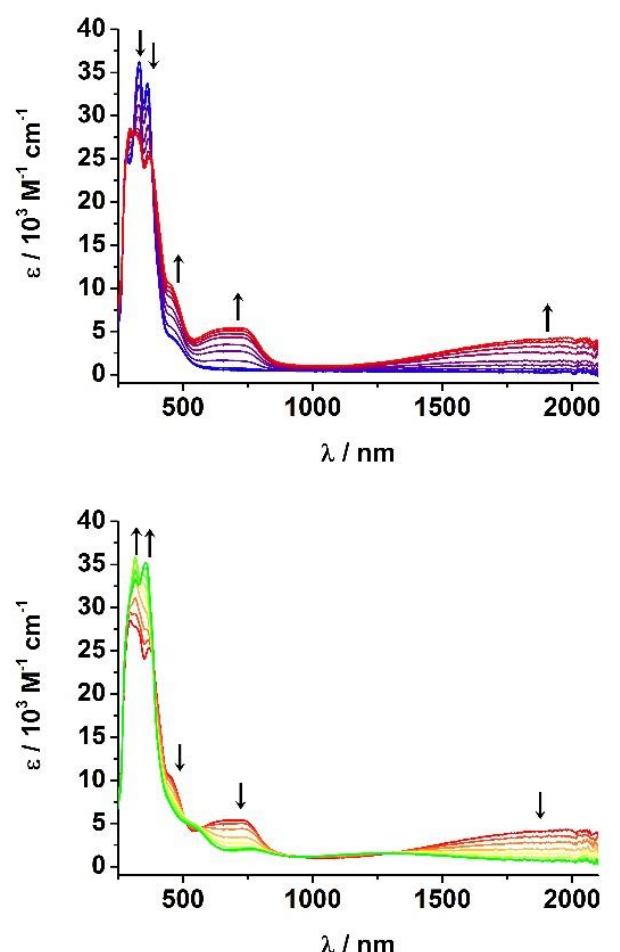

Figure S36. UV/vis/NIR spectroelectrochemistry of complex 2-OMe in 1,2-dichloroethane/ $\mathrm{NBu}_{4} \mathrm{PF}_{6}(0.1 \mathrm{M})$ at room temperature (blue line = neutral complex, red line = radical cation, green line $=$ dication).
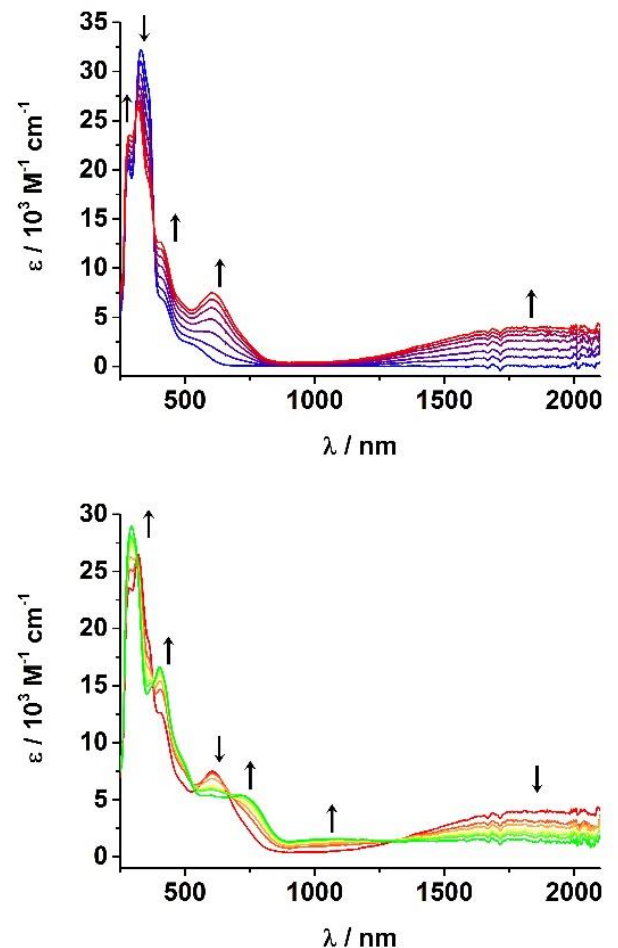

Figure S37. UV/vis/NIR spectroelectrochemistry of complex $\mathbf{2}-\mathbf{C F}_{\mathbf{3}}$ in 1,2-dichloroethane/ $\mathrm{NBu}_{4} \mathrm{PF}_{6}(0.1 \mathrm{M})$ at room temperature (blue line = neutral complex, red line = radical cation, green line $=$ dication). 

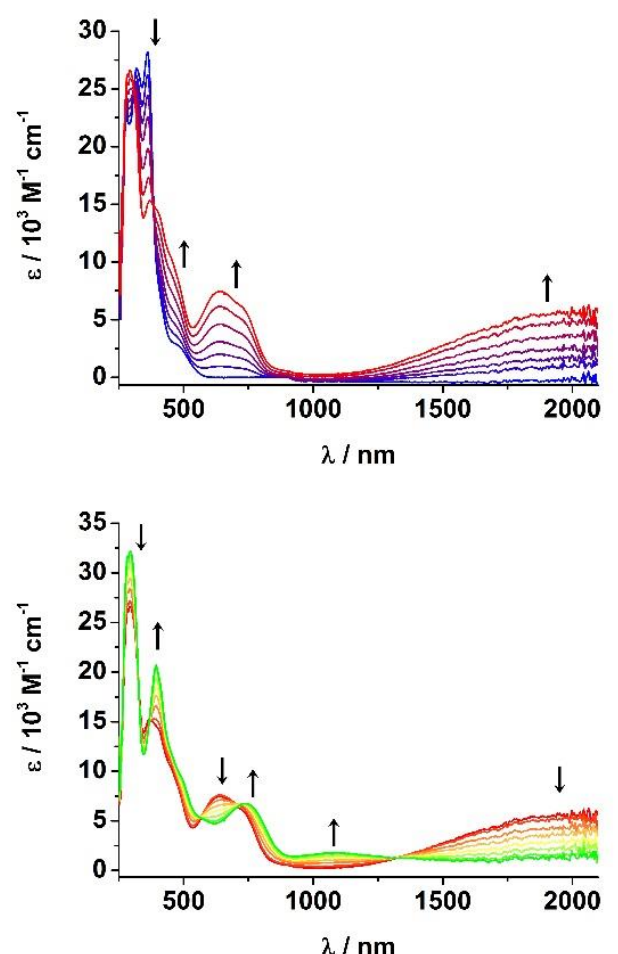

Figure S38. UV/vis/NIR spectroelectrochemistry of complex 2-D in 1,2-dichloroethane/ $\mathrm{NBu}_{4} \mathrm{PF}_{6}(0.1 \mathrm{M})$ at room temperature (blue line = neutral complex, red line = radical cation, green line $=$ dication $)$.
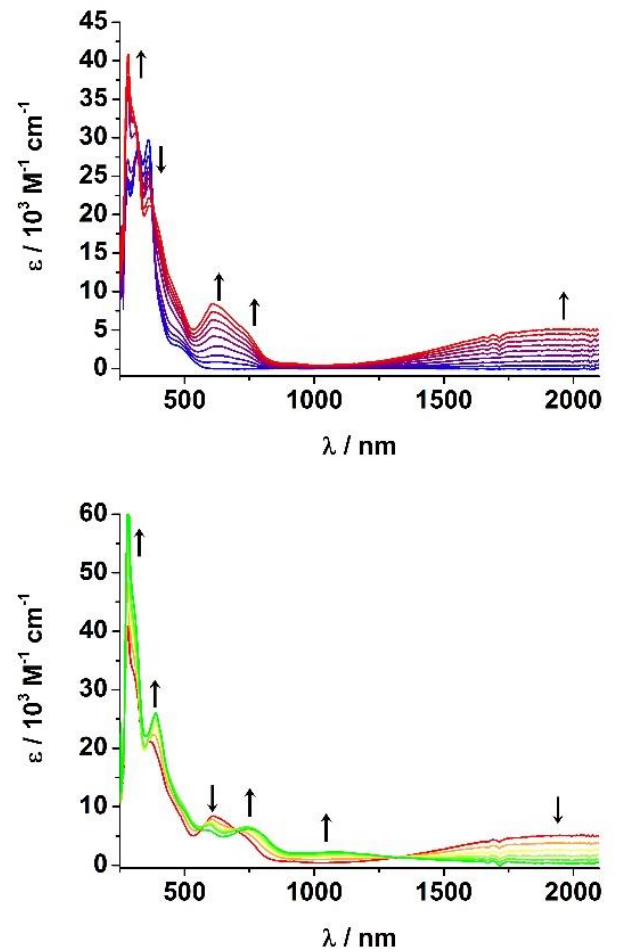

Figure S39. UV/vis/NIR spectroelectrochemistry of complex 2-F in 1,2-dichloroethane/ $\mathrm{NBu}_{4} \mathrm{PF}_{6}(0.1 \mathrm{M})$ at room temperature (blue line = neutral complex, red line $=$ radical cation, green line $=$ dication). 


\section{EPR spectra}

2-D
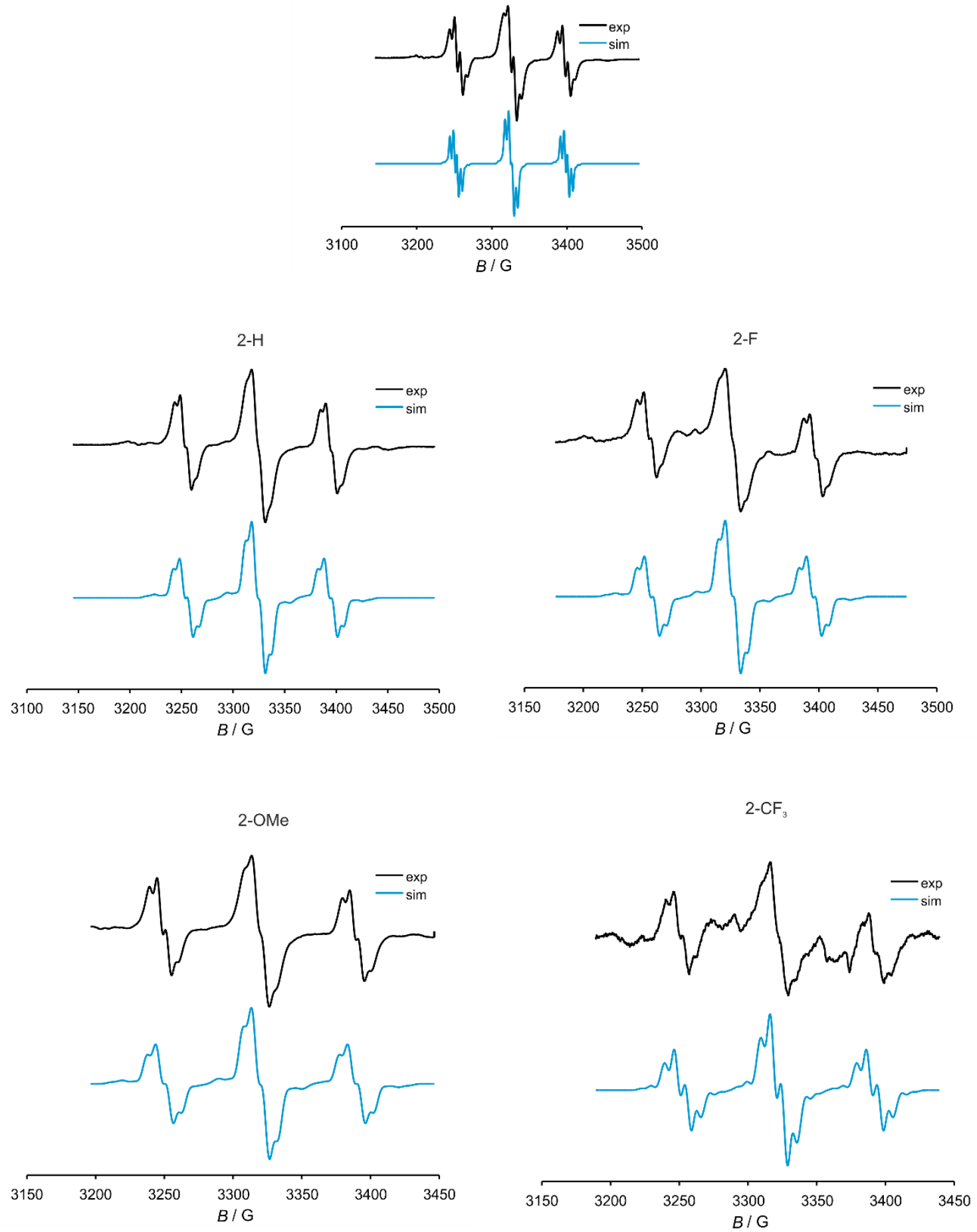

Figure S40. EPR spectra of the radical cations of the complexes at room temperature (black lines) and simulated spectra (blue lines). 


\section{Mößbauer spectra}

$1-\mathrm{OMe}$
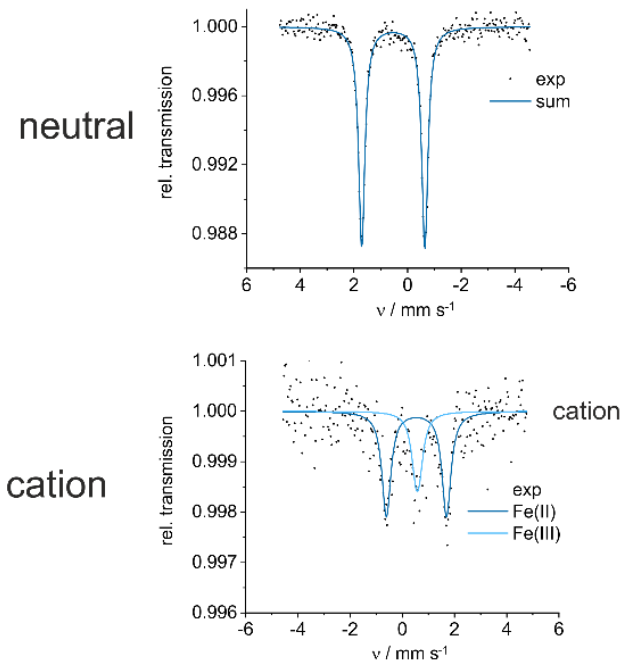

$1-\mathrm{H}$
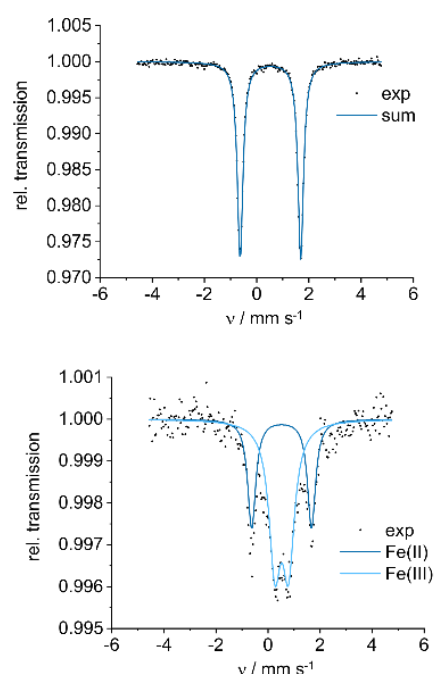

$1-\mathrm{CF} 3$
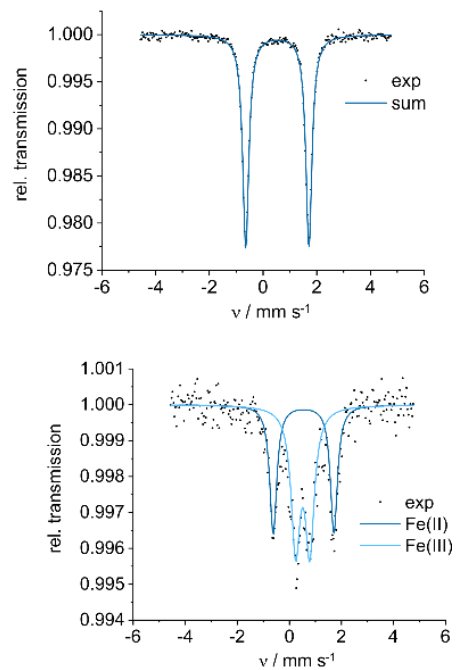

Figure S41. Mößbauer spectra of complexes 2-OMe, 2-H, and 2-CF in their neutral (top) and radical cationic forms (bottom) at $80 \mathrm{~K}$, referenced against $\alpha$-Fe.

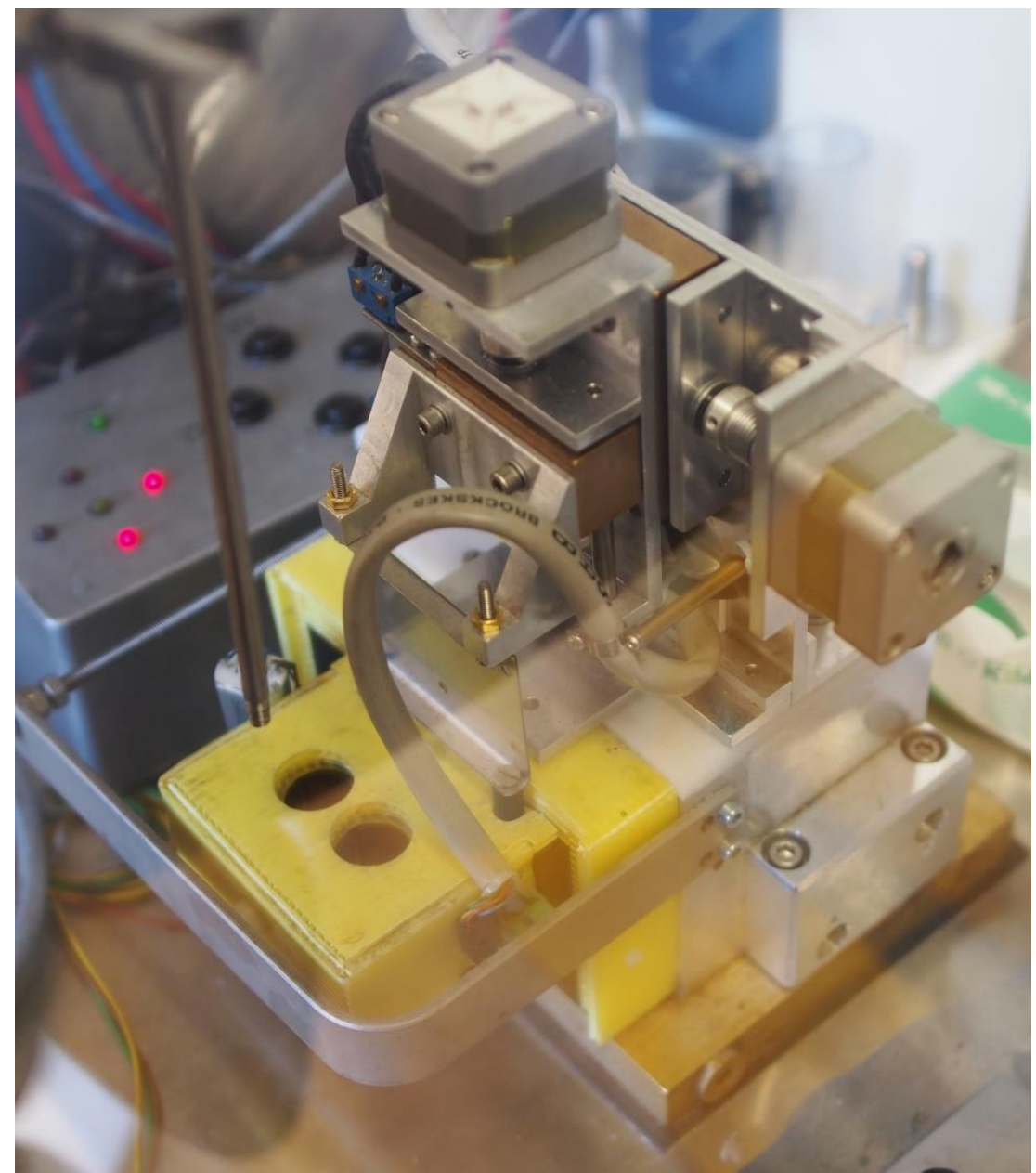

Figure S422. Photography of the setup used for the acquisition of $T$-dependent IR spectra. 